\title{
An Evolutionary Game Model to Study Manufacturers and Logistics Companies' Behavior Strategies for Information Transparency in Cold Chains
}

\author{
Xiao-Hu Xing, ${ }^{1}$ Zhi-Hua Hu $\mathbb{D}^{1},{ }^{1}$ Shu-Wen Wang, ${ }^{1}$ and Wen-Ping Luo ${ }^{2}$ \\ ${ }^{1}$ Logistics Research Center, Shanghai Maritime University, Shanghai 201306, China \\ ${ }^{2}$ School of Economical and Management, Shanghai Maritime University, Shanghai 201306, China \\ Correspondence should be addressed to Zhi-Hua Hu; zhhu@shmtu.edu.cn
}

Received 9 December 2019; Revised 23 March 2020; Accepted 30 March 2020; Published 21 April 2020

Academic Editor: Dongping Song

Copyright (C) 2020 Xiao-Hu Xing et al. This is an open access article distributed under the Creative Commons Attribution License, which permits unrestricted use, distribution, and reproduction in any medium, provided the original work is properly cited.

Cold goods manufacturers and logistics service providers are two essential groups of players in the goods safety issue in cold chains under the administration or inspection of governments and various stakeholders, including customers and final consumers. In this research, we applied the evolutionary game theory to examine the behavioral strategies of manufacturers and logistics service providers, while we formulated the governments and various other stakeholders' impacts by contracted subsidy and penalty. First, we developed an evolutionary game theory model of the interaction between manufacturers and logistics service providers. Then, we examined the evolutionary stable strategy (ESS) of the manufacturers and logistics service providers under various constraints. Finally, we used simulation to demonstrate the impact of combinations of various parameters on the ESS and evolutionary paths. The results showed that the behavior strategies of the manufacturers and logistics service providers are interleaved and affected by the parameters in the developed model. We analyzed the ESSs and evolutionary paths by considering profits of the cold goods, the cold chain logistics costs, mainly the additional profits and costs of sharing information, and the subsidy and penalty regulated by contracts and governments. By tuning the parameters for numerical studies, we can find that the subsidy and penalty are essential for the cold chain manufactures and logistics service providers to adopt the information-sharing strategy, while the cost of the strategy and the profit of them constrains the positivity. Although, besides instant costs and profits, the information-sharing strategy can add values to cold chains in the long run, the administrators must consider the two populations of players and advocate them to adopt the information-sharing strategy consistently by using optimal policies.

\section{Introduction}

In cold chains, safety problems of fresh goods frequently happen because of the temperature out of control, especially in the logistics processes [1]. Economically, the temperature is not well controlled due to technology investment and cost reasons. In the context of food quality and safety, the stakeholders in cold chains believe that it is beneficial to visualize the cold chains based on the information transparency technologies and mechanisms [2]. Besides, the increasing degree of information transparency helps the administration of the cold chain by the stakeholders and the related governmental departments.

In cold chains, the manufacturers, as cold food suppliers and specialized logistics service providers, are two relevant stakeholders. The logistics service providers usually undertake the transportation and warehousing processes from the manufacturers to the customers (typically retailers or final consumers). Generally, the manufacturers will make contracts with the logistics service providers to maintain the temperature during the whole logistics process so that they can control the food quality. The logistics service providers should share the information in the logistics processes to the manufacturers and related government departments, even the related customers and final consumers. So, various sensors, wireless sensor networks, and even the Internet of things should be applicable in the logistics facilities and devices $[1,3]$. By these technologies and devices, the temperature and other quality-related information can be 
sensed, transported, and shared. However, different logistics operators may use different technologies, and the information transparency degree is affected by various factors. Notably, the manufacturers usually outsource the logistics processes to various local companies, which makes the information less transparent. Besides, some companies may hesitate to share information due to distrust and competition. On the manufacturer's and customer's sides, information transparency is a crucial way to inspect the temperature status and administrate the distributive logistics processes.

To study this dilemma and the mutual interactions between the manufacturers and logistics service providers in cold chains, an evolutionary game $[4,5]$ is used to formulate the information transparency mechanisms. We consider the manufacturers and logistics service providers as two populations with dynamic interactions, while the evolutionary game models are capable of studying the dynamics between populations. The manufacturers and logistics service providers adjust the strategies according to the feedbacks in the cold chain markets. We studied the penalty and various interference costs and returns in the context of contracts between manufacturers and logistics service providers without considering the third-party coordination organizations. However, the related government departments and industrial organizations can regulate the business in the cold chain, primarily due to food safety issues.

This study contributes to the literature in the following aspects. First, although some studies have examined information transparency or information sharing issues in logistics [6], cold chain logistics is not studied. However, the temperature control features the cold chain, especially for safety problems [1], and so the information transparency incurs additional investment and administration. Meanwhile, the evolutionary game is an essential tool to examine the behavior strategy of information transparency [7] in the context of cold chains. Second, some pioneering studies have examined the technologies, devices, operations, and even information systems for cold chain logistics [8], while they did not investigate the dynamics among the main stakeholders (here manufacturers and logistics service providers). An evolutionary game model contributes to analyzing such dynamics. Third, although many pioneering studies using evolutionary games in supply chains provide useful references for this study, the administrators must consider the costs and benefits induced by temperature control technologies and processes and governments' different roles to extend these existing studies to cold chains.

In the following sections, we firstly review the studies related to information transparency, cold chain logistics, and evolutionary games in supply chains. Then, we elucidate the research problem with the assumptions in Section 3. Section 4 developed formulations and model analysis. In Section 5, we conduct numerical studies. Section 6 concludes the study.

\section{Related Studies}

2.1. Information Transparency in Logistics. To inspect and manage the temperature-controlled cold chains, the stakeholders must provide the relation information interfaces connected with the logistics facilities and devices. Information transparency is a concept to represent the easiness of accessing the information shared among the stakeholders in the cold chain. However, we can seldom find the researches in the context of cold chain logistics, while the communities of logistics and supply chains have published some pioneering studies.

In Table 1, we reviewed the pioneering studies on logistics information transparency in three dimensions. First, information transparency coincides with information sharing. In the "Issue" column, "RFID" is a hot topic, especially from several years ago. The Internet of Things (IoTs) plays an essential role in information transparency in logistics and supply chains, including cold chains. Investments and risks have been identified and studied because investments in technologies and devices must pay the value information transparency. The "Stakeholders" mainly include the members in supply chains and the governments. In Table 1, two studies examine the logistics service providers $[6,19]$ in the context of supply chains.

2.2. Cold Chain Logistics. A cold chain is a temperaturecontrolled supply chain, where the technologies, devices, and management systems play essential roles in the processes of the cold chain. Logistics makes the cold chain temperature control much complicate because the facilities and processes are usually distributive and undertaken by various stakeholders and even outsourcing. The industry has developed the technology aspect of the cold chain well, notably including refrigerators and power technologies. The information and system aspects are highly related to this study. In Table 2, we reviewed the studies to present the typical issues examined in the literature and the methods used. We classify the issues into three categories: operations research, operations management, and systems. In cold chain systems, sustainability and safety issues are increasingly concerned. Furthermore, we classify the issues into logistics problems and supply chain problems. The research methods include assessment, optimization algorithms, empirical and case studies, and review.

\subsection{Evolutionary Games in Supply Chain Studies.} Evolutionary game is a tool to study the dynamic evolutionary strategies between two interacted populations by establishing and analyzing the replicator dynamic systems. The pioneering studies have developed evolutionary games for policymaking problems and the behavior strategies of interreacted stakeholders. Although the evolutionary game is also widely used to study the supply chain, the cold chain is seldom examined by it. Therefore, in Table 3, 12 studies in supply chain management (SCM) are reviewed. Mainly the issues and the interacted populations are summarized. In the studied issues, most papers studied sustainability (also including green, low carbon, and remanufacturing behavior strategies), while these papers also examined the risk and knowledge-sharing issues. The populations involved mainly include production supply chain members (typically 
TABLE 1: Studies in logistics information transparency.

\begin{tabular}{|c|c|c|c|}
\hline Study & Issue & Stakeholders & Method \\
\hline [9] & Information integration and profitability & Manufacturers, retailers & $\begin{array}{l}\text { Conceptual } \\
\text { model }\end{array}$ \\
\hline [10] & $\begin{array}{c}\text { Information sharing, supply uncertainty, and demand } \\
\text { volatility }\end{array}$ & Manufacturer, retailers & Simulation \\
\hline [11] & Role of information sharing in SCE & Vendors, retailers & Case study \\
\hline [12] & Information flows in SCEs & Buyers, suppliers & Data analysis \\
\hline [13] & RFID investment & SCE & Survey \\
\hline$[14]$ & RFID-enabled business intelligence & Manufacturers, distributors & IS \\
\hline [15] & Information sharing and investment in procurement & Suppliers, buyers & Game model \\
\hline [8] & RFID information sharing and exchanging & Governments, enterprises & IS \\
\hline [16] & RFID investment risk and gain reallocation & SCE & Risk assessment \\
\hline [17] & $\begin{array}{l}\text { Information sharing, environmental and economic } \\
\text { benefits }\end{array}$ & Manufacturers, suppliers & Inventory model \\
\hline [18] & Information linkages with retailers & Multinational companies and retailers & Case study \\
\hline [19] & Information sharing of VMI & TPL, its customer & Inventory model \\
\hline [20] & Information sharing and safety traceability & Producers, distributors, and ordinary users & IS \\
\hline [6] & Blockchain and information sharing & $\begin{array}{c}\text { Manufacturer, supplier, and logistics service } \\
\text { integrator }\end{array}$ & Stackelberg game \\
\hline [21] & Food traceability & Farmers, traders, and consumers & Case study \\
\hline
\end{tabular}

Note. IS = information system; RFID = radio frequency identification; $\mathrm{SCE}=$ supply chain enterprises; TPL $=$ third-party logistics.

TABle 2: Studies in cold chain logistics.

\begin{tabular}{lcc}
\hline Study & Issues & Methods \\
\hline$[22]$ & Performance evaluation & Assessment \\
{$[23]$} & Logistics competence & AHP, FCE \\
{$[24]$} & Distribution network & GA \\
{$[25]$} & VRPTW & GA \\
{$[26]$} & Sustainable distribution & MILP \\
{$[27]$} & Disruption management & Partial least squares \\
{$[28]$} & Perishable product & Empirical study \\
{$[29]$} & Data-driven decision-making & Review \\
{$[30]$} & Recommender systems & Heuristics algorithm \\
{$[31]$} & Value-added service & Case study \\
{$[32]$} & Distribution optimization & PSO \\
{$[33]$} & Integrated IRP & GSAA \\
{$[34]$} & Sustainability & Graph theory \\
{$[35]$} & Distribution optimization & GA \\
{$[36]$} & Vehicle routing problem & Heuristics algorithm \\
\hline
\end{tabular}

Notes. AHP = analytic hierarchy process; FCE = fuzzy comprehensive evaluation; $\mathrm{GA}=$ genetic algorithm; GSAA = genetic simulated annealing algorithm; IRP = inventory routing problem; $\mathrm{MILP}=$ mixed-integer linear program; $\mathrm{PSO}=$ particle swarm optimization; $\mathrm{VRPTW}=$ vehicle routing problem with time windows.

manufacturers, suppliers, and retailers) and governments. These studies do not study logistics service providers or other entities related to logistics.

\section{Problem Description and Assumptions}

3.1. Problem Description. As estimated by [52], the global cold chain market will probably reach approximately USD 269.61 billion by 2024, growing at a CAGR of around 7.5\% between 2018 and 2024. The cold chain is a system for the management and transportation of temperature-sensitive products through refrigerated and thermal methods of packaging. A cold chain is a temperature-controlled supply chain from the manufacturers of the cold goods to final customers. Unlike other goods, cold chain goods are perishable and sensitive to temperature changes. So, cold chain logistics is not just a process of warehousing and transportation. Its validity involves innovative technologies, devices, and managerial systems to ensure temperature control and maintenance in the whole logistics process. Simultaneously, the natures of the cold chain goods are different and demand different temperature control technologies, methods, and devices, which involve knowledge transfer from the manufacturers to the logistics service providers.

In a cold chain, various stakeholders are involved. The manufacturers and logistics service providers are two roles strictly related to ensuring the cold chain goods quality and the key players in temperature control. In the logistics scenarios, from the manufacturers to the final customers, the cold goods are stored and transported through various warehouses and containers by trucks, trains, ships, and other means. Therefore, it is challenging to manage the timevarying status of cold goods when the cold chain is not transparent. In the cold chain, the individual logistics service suppliers can apply various technologies and devices to control the temperature, while these devices are not well connected. So, it is beneficial for the logistics service provider to connect the logistics processes (even devices) when the information acquired by these processes is shared, at least in the cold chain. Although the devices and their collected data may even be not credible and traceable, the information transparency degree deduced by information sharing in the cold chain is a way to manage the cold goods' temperature. As analyzed above, technology and devise investments contribute to the additional costs of logistics. When the investment costs still restrict the whole industry, the tradeoff and evolutionary games between the manufacturers and logistics service providers may determine the development tendency of the cold chain ecosystem. In the 
TABLE 3: Studies of evolutionary games in supply chain management.

\begin{tabular}{lcc}
\hline Study & Issues & Populations \\
\hline$[37]$ & Behavior strategies triggering green practices & Producers, retailers \\
{$[38]$} & Remanufacturing closed-loop supply chain & Manufacturers, retailers \\
{$[39]$} & Green SCM diffusion & Governors, enterprises \\
{$[40]$} & Long-term green purchasing relationships & Suppliers, manufacturers \\
{$[41]$} & Energy source selection & Government, power plants \\
{$[42]$} & Low-carbon investment strategies & Suppliers, manufacturers \\
{$[43]$} & Financial risk cooperation behaviors & Suppliers, manufacturers \\
{$[44]$} & Sustainability and government intervention & Governors, producers \\
{$[45]$} & Wholesale-retail pricing strategies & Manufacturer, retailers \\
{$[46]$} & Cooperation relationships and tendency & Constructors, suppliers \\
{$[47]$} & Remanufacturers competing for leadership & Manufacturers, retailers \\
{$[48]$} & Green investment strategies with subsidy & Manufacturers, suppliers \\
{$[49]$} & Low-carbon behaviors, strategies, and policies & Retailers, manufacturers \\
{$[50]$} & Knowledge-sharing behavior and alliance & Construction enterprises \\
{$[51]$} & Green production and financial intervention & Suppliers, manufacturers, and governments \\
\hline
\end{tabular}

following study, we employ an evolutionary game to study the information transparency mechanisms between these two key stakeholders (manufacturers and logistics service providers) in a cold chain.

On the side of logistics service providers, to organize the temperature-controlled cold chain logistics processes, the following information is beneficial: the food status (original temperature and quality), the refrigerator technologies suitable for the food, and the restrict time and temperature standards allowed for food package handlings for warehousing and transshipment [3]. The stakeholders can negotiate possible other demands in the contracts for ensuring food quality in logistics. These information aspects affect the costs and efficiencies of logistics, and so the risks and profits are different from the logistics service providers. Wellcontrolled information transparency in cold chains incurs increasing costs and responsibilities to the manufacturers and logistics service providers.

As analyzed above, in cold chains, information transparency incurs two-sided effects. On the one side, information transparency can increase food safety and satisfaction degrees by propelling companies to share their information related to temperature control by using various advanced refrigerator and information technologies. On the other side, information sharing for increasing information transparency incurs technology investment and management costs, operations risks, and possible competitions [53]. Therefore, it is a dilemma for companies to increase information transparency in the whole cold chain industry. Various food safety events frequently happen, while the cold chain technologies and markets are developing very fast at the same time [27].

3.2. Model Assumption. In the context of evolutionary games, cold chain manufacturers and logistics service providers are two distinct groups of companies as two populations of players. The individual player in a population behaves under the affection of other players in the same population. They will stimulate each other. The mutual interactions between the players from the two populations will directly affect the behaviors of the two players and, thus, as a whole affect the populations' behaviors [54]. The individuals in the same population can share behavior information in a manner of cooperation.

In cold chains, as for information transparency, manufacturers and logistics service providers may cooperate and not cooperate in propelling information sharing. The possibilities of adopting the cooperation strategy are denoted by $x$ and $y(x, y \in[0,1])$ for the two populations; inversely, the possibilities of not adopting the cooperation strategy are $(1-x)$ and $(1-y)$. In an evolutionary game, these possibilities evolve and present dynamics.

In cold chain logistics, advocating information transparency incurs an additional cost (denoted by $C$ ) for the infrastructures of sensors, communication networks, and application systems. The logistics service provider may obtain the additional profit (denoted by $P$ ) due to market acceptance. When a manufacturer does not share information, the unit profit of cold goods production is $\pi_{A}$, while the logistics service provider can just manage the cold chain by general cold chain practices. The logistics service provider can obtain the profit $\left(\pi_{B}\right)$, when the company does not choose the strategy of cooperation. When the manufacturer and the logistics service provider cooperate closely, they can obtain profit $P$ from the market, and they can undertake the cost $C$ cooperatively. In the cooperation (information sharing for information transparency) strategy in the evolutionary game, when one player shares information while another does, a penalty (denoted by $F$ ) will incur to the one that does not choose cooperation; simultaneously, the one choosing to share information will obtain a subsidy $V$. The penalty and subsidy mechanisms can be contracted and administrated by the governments.

Information transparency will benefit the stakeholders in the cold chains, including customers and administration departments. So, the improvement of food safety due to information transparency may result in the readjusting of the market. The administrators should reallocate the induced surplus of the additional profit between the manufacturer and the logistics service provider. The amount allocated to the manufacturer is denoted by a proportion, $\alpha$ $(\alpha \in[0,1])$; thus, the logistics service provider can obtain $(1-\alpha)$. Simultaneously, the cost also will be allocated to the 
manufacturer $(\beta)$ and the logistics service provider $(1-\beta)$, $\beta \in[0,1]$. The values of $(\alpha, \beta)$ will affect the evolutionary tendencies of the game and should be negotiated in practice.

\section{Formulations and Model Analysis}

4.1. Payoff Matrix. Considering the assumptions and notations elucidated in Section 3.2, the payoff matrix between the cold chain manufacturer and logistics service provider is presented in Table 4. The additional cost and profit are reallocated to the players when at least one player chooses the cooperation for information sharing in the information transparency mechanisms.

4.2. Replicator Dynamic System. Based on the payoff matrix (Table 1), the average profit obtained by the cold chain manufacturers when the cooperation strategy (denoted by $F_{\mathrm{co}}$ ) is dominant is computed as (1). Similarly, the average profit of the manufacturers when cooperation is adopted $\left(F_{\text {noco }}\right)$ is formulated by (2). Synthesizing (1) and (2), the average profit obtained by the manufacturer $(\bar{F})$ is formulated by $(3)$. Then, the replicator dynamic equation of the manufacturers adopting the cooperation strategy is formulated by (4):

$$
\begin{aligned}
F_{\mathrm{co}} & =y\left(\pi_{A}+\alpha P-\beta C\right)+(1-y)\left(\pi_{A}-\beta C+V\right), \\
F_{\text {noco }} & =y\left(\pi_{A}-F\right)+(1-y)\left(\pi_{A}\right), \\
\bar{F} & =x F_{\mathrm{co}}+(1-x) F_{\text {noco }}, \\
F(x) & =\frac{\mathrm{d} x}{\mathrm{~d} t}=x\left(F_{\mathrm{co}}-\bar{F}\right)=x(1-x)\left[F_{\mathrm{co}}-F_{\text {noco }}\right] \\
& =x(1-x)[(\alpha P-V+F) y-\beta C+V] .
\end{aligned}
$$

Like (1)-(4), the logistics service provider's average profits when it adopts cooperation and non-cooperation strategies $\left(E_{\mathrm{co}}\right.$ and $\left.E_{\text {noco }}\right)$ are formulated by (5) and (6). So, the overall average profit $(\bar{E})$ is computed by $(7)$. Thus, the replicator dynamic equation $(E(y))$ is given in (8):

$$
\begin{aligned}
E_{\mathrm{co}}= & x\left(\pi_{B}+(1-\alpha) P-(1-\beta) C\right) \\
& +(1-x)\left(\pi_{B}-(1-\beta) C+V\right), \\
E_{\mathrm{noco}}= & x\left(\pi_{B}-F\right)+(1-x)\left(E_{B}\right), \\
\bar{E}= & y E_{\mathrm{co}}+(1-y) E_{\mathrm{noco}}, \\
E(y)= & \frac{\mathrm{d} y}{\mathrm{~d} t}=y\left(E_{\mathrm{co}}-\bar{E}\right)=y(1-y)[x((1-\alpha) P-V+F) \\
& -(1-\beta) C+V] .
\end{aligned}
$$

4.3. Evolutionary Equilibrium Point. Combining (4) and (5), we developed a replicator dynamic system in (9). The values of $x$ and $y$ of an evolutionary stable strategy (ESS) should meet $F(x)=F(y)=0$ in (9). Under these two equations, we can obtain two groups of ESS as (10) and (11). We then can derive five equilibrium points (EPs) from the dynamic system (9) in the domain $s=\{(x, y) \mid 0 \leq x, y \leq 1\}$. These EPs are denoted by $E_{1}(0,0), E_{2}(0,1), E_{3}(1,0), E_{4}(1,1)$, $E_{5}\left(x_{*}, y_{*}\right), x_{*} \in[0,1]$, and $y_{*} \in[0,1]$ :

$$
\left\{\begin{array}{l}
F(x)=x(1-x)[(\alpha P-V+F) y-\beta C+V], \\
E(y)=y(1-y)[x((1-\alpha) P-V+F)-(1-\beta) C+V],
\end{array}\right.
$$

$$
\begin{aligned}
& x_{1}=0, \\
& x_{2}=1, \\
& y_{*}=\frac{\beta C-V}{\alpha P-V+F}, \\
& y_{1}=0, \\
& y_{2}=1, \\
& x_{*}=\frac{(1-\beta) C-V}{(1-\alpha) P-V+F} .
\end{aligned}
$$

4.4. ESS Analysis. We analyze the equilibrium points' stability by using the stability of the Jacobian matrix of the replicator dynamic system. Firstly, we derive the Jacobian matrix (denoted by $J$ ) in (12). The determinant $(\operatorname{det} J)$ and $\operatorname{trace}(\operatorname{tr} J)$ of $J$ are then computed in (13) and (14) individually. The equilibrium points satisfying $\{\operatorname{det} J>0, \operatorname{tr} J<0\}$ are stable points of the replicator dynamic system. The det $J$ and $\operatorname{tr} J$ of the five equilibrium points are computed as Table 5 by using (13) and (14):

$$
J=\left[\begin{array}{ll}
\frac{\partial F(x)}{\partial x} & \frac{\partial F(x)}{\partial y} \\
\frac{\partial E(y)}{\partial x} & \frac{\partial E(y)}{\partial y}
\end{array}\right],
$$

$$
\left\{\begin{array}{l}
\frac{\partial F(x)}{\partial x}=(1-2 x)[(\alpha P-V+F) y-\beta C+V], \\
\frac{\partial F(x)}{\partial y}=(\alpha P-V+F) x(1-x), \\
\frac{\partial E(y)}{\partial x}=((1-\alpha) P-V+F) y(1-y), \\
\frac{\partial E(y)}{\partial y}=(1-2 y)[x((1-\alpha) P-V+F)-(1-\beta) C+V],
\end{array}\right.
$$

$$
\begin{aligned}
\operatorname{det} J= & (1-2 x)[(\alpha P-V+F) y-\beta C+V] \\
& \cdot(1-2 y)[x((1-\alpha) P-V+F)-(1-\beta) C+V] \\
& -(\alpha P-V+F) x(1-x)((1-\alpha) P-V+F) y(1-y),
\end{aligned}
$$


TABle 4: Payoff matrix.

\begin{tabular}{|c|c|c|c|}
\hline & & Logis & ovider \\
\hline & & Cooperation $(y)$ & Non-cooperation $(1-y)$ \\
\hline Manufacturer & Cooperation $(x)$ & $\begin{array}{c}\pi_{A}+\alpha P-\beta C \\
\pi_{B}+(1-\alpha) P-(1-\beta) C\end{array}$ & $\begin{array}{c}\pi_{A}-\beta C+V \\
\pi_{B}-F\end{array}$ \\
\hline Manufacturer & Non-cooperation $(1-x)$ & $\begin{array}{c}\pi_{A}-F \\
\pi_{B}-(1-\beta) C+V\end{array}$ & $\begin{array}{l}\pi_{A} \\
\pi_{B}\end{array}$ \\
\hline
\end{tabular}

TABle 5: The $\operatorname{det} J$ and $\operatorname{tr} J$ of the five equilibrium points.

\begin{tabular}{lcc}
\hline EP & $\operatorname{det} J$ & $\operatorname{tr} J$ \\
\hline$E_{1}(0,0)$ & $(-\beta C+V)[-(1-\beta) C+V]$ & $2 V-C$ \\
$E_{2}(1,0)$ & $-(-\beta C+V)((1-\alpha) P-(1-\beta) C+F)$ & $(1-\alpha) P+\beta C+F-(1-\beta) C-V$ \\
$E_{3}(0,1)$ & $(\alpha P+F-\beta C)(-)(-(1-\beta) C+F)$ & $-\alpha P+\beta C-(1-\beta) C$ \\
$E_{4}(1,1)$ & $-(\alpha P+F-\beta C)-((1-\alpha) P+F-(1-\beta) C)$ & $C-2 F-P$ \\
$E_{5}\left(x_{*}, y_{*}\right)$ & $\Delta$ & 0 \\
\hline
\end{tabular}

Note. $\Delta=-[(1-\beta) C-V](((1-\alpha) P+F-(1-\beta) C) /((1-\alpha) P-V+F))[\beta C-V]((\alpha P+F-\beta C) /(\alpha P-V+F))$.

$$
\begin{aligned}
\operatorname{tr} J= & (1-2 x)[(\alpha P-V+F) y-\beta C+V]+(1-2 y) \\
& \cdot[x((1-\alpha) P-V+F)-(1-\beta) C+V] .
\end{aligned}
$$

(1) $E_{1}(0,0)$ is an ESS when $\{(-\beta C+V)[-(1-\beta) C+V]>0 ; 2 V-C<0\}$ is met. Because of $-\beta C+V \leq 0$ and $-(1-\beta) C+V \leq 0$, we can obtain $V<\beta C$ and $V<(1-\beta) C$. It indicates that when the subsidy cannot compensate for the cooperation cost, the cold chain manufacturer and the logistics service provider will give up the cooperation by sharing information.

(2) $E_{2}(1,0)$ is an ESS when $\{-(-\beta C+V)((1-\alpha) P-$ $(1-\beta) C+F)>0 ;(1-\alpha) P+\beta C+F-(1-\beta) C-V$ $<0\}$, we can deduce that $\{\beta C-V \leq 0 ;(1-\alpha)$ $P-(1-\beta) C+F \leq 0\}$. So, $V>\beta C$ and $(1-\beta) C>$ $(1-\alpha) P+F$. Under this ESS, the cold chain manufacturer undertakes less cost; the logistics service provider obtains minor profit. Comparatively, $\alpha$ is big, while $\beta$ is small.

(3) $E_{3}(0,1)$ is an ESS when $\{-(\alpha P+F-\beta C)(-(1-$ $\beta) C+F)>0 ; \alpha P-V+F<0\}$ is met. Setting $\{-\alpha P-F+\beta C \leq 0 ;-(-(1-\beta) C+F) \leq 0\}$, we can get $\{\beta C>\alpha P+F ; F>(1-\beta) C\}$. Under this ESS, $\beta$ is small and $\alpha$ is big, while the subsidy $V$ should be big comparatively.

(4) $E_{4}(1,1)$ is an ESS when $\{-(\alpha P+F-\beta C)-((1-\alpha)$ $P+F-(1-\beta) C)>0 ; C-2 F-P<0\}$ is met. When $-(\alpha P+F-\beta C)<0$ and $-((1-\alpha) P+F-(1-\beta) C)$ $<0$, we can get $\beta C<\alpha P+F$ and $(1-\beta) C$ $<(1-\alpha) P+F$. In this ESS, $\beta$ is big. So, the cold chain manufacturer undertakes more cost than the additional profit and the penalty paid by the logistics service providers; the cost undertaken by the logistics service provider is also beyond the profit and the penalty paid by the logistics service providers. Two times of additional profit and subsidy are more significant than the cost of information sharing.
We classify the studies on the ESSs into four parts in Tables 6-9 considering the inequalities between $V$ and $\beta C$ and the inequalities between $V$ and $(1-\beta) C$.

(1) Category 1: $V<\beta C$ and $V<(1-\beta) C$

(1) In Category 1.1, $(1-\beta) C>(1-\alpha) P+F$, $\beta C<\alpha P+F$, and $F<(1-\beta) C$. The subsidy cannot compensate for the cost of information sharing to the manufacturers and logistics service providers. The information-sharing cost of the logistics service providers is higher than the additional profit and penalty (obtained from the manufacturers when they do not adopt the cooperation strategy). In summary, the subsidy is low, the profit is low, the information-sharing cost is high, and the penalty to the non-cooperation strategy is low. An ESS exists, $E_{2}(0,0)$, and both players will give up the cooperation of sharing information.

(2) In Category 1.2, $(1-\beta) C>(1-\alpha) P+F$, $\beta C>\alpha P+F$, and $F<(1-\beta) C$. For the manufacturers and logistics service providers, the cost of sharing information is high, while the subsidy, the additional profit deduced by information sharing, and the penalty cost deduced by noncooperation are low. Here, the ESS is $E_{2}(0,0)$. Thus, both players will give up the cooperation strategy.

(3) In Category 1.3, $(1-\beta) C<(1-\alpha) P+F$, $\beta C<\alpha P+F$, and $F<(1-\beta) C$. For both players, the cost of sharing information, the subsidy, and the penalty cost of non-cooperation strategy are all low. Affected by the additional profit $P$, two ESSs will occur: $E_{2}(0,0)$ and $E_{4}(1,1)$. The players will choose cooperation or non-cooperation strategies according to the additional profit.

(4) In Category $1.4,(1-\beta) C<(1-\alpha) P+F$, $\beta C<\alpha P+F$, and $F>(1-\beta) C$. For both players, the cost of sharing information and the subsidy is 
TABLe 6: Local stability analysis $(V<\beta C$ and $V<(1-\beta) C)$.

\begin{tabular}{|c|c|c|c|c|c|c|}
\hline No. & Figure & Constraints & EP & $\operatorname{det} J$ & $\operatorname{tr} J$ & State \\
\hline 1 & Figure $1(\mathrm{a})$ & $\begin{array}{c}V<\beta C, V<(1-\beta) C \\
(1-\beta) C>(1-\alpha) P+F \\
\beta C<\alpha P+F, F<(1-\beta) C\end{array}$ & $\begin{array}{c}E_{1}(0,0) \\
E_{2}(1,0) \\
E_{3}(0,1) \\
E_{4}(1,1) \\
E_{5}\left(x_{*}, y_{*}\right)\end{array}$ & $\begin{array}{l}+ \\
- \\
+ \\
- \\
\Delta\end{array}$ & $\begin{array}{l}- \\
+ \\
0\end{array}$ & $\begin{array}{c}\text { ESS } \\
\text { Saddle point } \\
\text { Instability point } \\
\text { Saddle point }\end{array}$ \\
\hline $2 \#$ & & $\begin{array}{c}V<\beta C, V<(1-\beta) C \\
(1-\beta) C>(1-\alpha) P+F \\
\beta C<\alpha P+F, F>(1-\beta) C\end{array}$ & $\begin{array}{c}E_{1}(0,0) \\
E_{2}(1,0) \\
E_{3}(0,1) \\
E_{4}(1,1) \\
E_{5}\left(x_{*}, y_{*}\right)\end{array}$ & $\begin{array}{l}+ \\
- \\
- \\
- \\
\Delta\end{array}$ & - & $\begin{array}{c}\text { ESS } \\
\text { Saddle point } \\
\text { Saddle point } \\
\text { Saddle point }\end{array}$ \\
\hline 3 & Figure $1(\mathrm{~b})$ & $\begin{array}{c}V<\beta C, V<(1-\beta) C \\
(1-\beta) C>(1-\alpha) P+F \\
\beta C>\alpha P+F, F<(1-\beta) C\end{array}$ & $\begin{array}{c}E_{1}(0,0) \\
E_{2}(1,0) \\
E_{3}(0,1) \\
E_{4}(1,1) \\
E_{5}\left(x_{*}, y_{*}\right)\end{array}$ & $\begin{array}{l}+ \\
- \\
- \\
+ \\
\Delta\end{array}$ & $\begin{array}{l}- \\
+ \\
+\end{array}$ & $\begin{array}{c}\text { ESS } \\
\text { Saddle point } \\
\text { Saddle point } \\
\text { Instability point }\end{array}$ \\
\hline $4 \#$ & & $\begin{array}{c}V<\beta C, V<(1-\beta) C \\
(1-\beta) C>(1-\alpha) P+F \\
\beta C>\alpha P+F, F>(1-\beta) C\end{array}$ & $\begin{array}{c}E_{1}(0,0) \\
E_{2}(1,0) \\
E_{3}(0,1) \\
E_{4}(1,1) \\
E_{5}\left(x_{*}, y_{*}\right)\end{array}$ & $\begin{array}{l}+ \\
- \\
+ \\
+ \\
\Delta\end{array}$ & $\begin{array}{l}- \\
- \\
+\end{array}$ & $\begin{array}{c}\text { ESS } \\
\text { Saddle point } \\
\text { ESS } \\
\text { Instability point }\end{array}$ \\
\hline 5 & Figure $1(\mathrm{c})$ & $\begin{array}{c}V<\beta C, V<(1-\beta) C \\
(1-\beta) C<(1-\alpha) P+F \\
\beta C<\alpha P+F, F<(1-\beta) C\end{array}$ & $\begin{array}{c}E_{1}(0,0) \\
E_{2}(1,0) \\
E_{3}(0,1) \\
E_{4}(1,1) \\
E_{5}\left(x_{*}, y_{*}\right)\end{array}$ & $\begin{array}{l}+ \\
+ \\
+ \\
+ \\
\Delta\end{array}$ & $\begin{array}{l}- \\
+ \\
+ \\
-\end{array}$ & $\begin{array}{c}\text { ESS } \\
\text { Instability point } \\
\text { Instability point } \\
\text { ESS }\end{array}$ \\
\hline 6 & Figure $1(\mathrm{~d})$ & $\begin{array}{c}V<\beta C, V<(1-\beta) C \\
(1-\beta) C<(1-\alpha) P+F \\
\beta C<\alpha P+F, F>(1-\beta) C\end{array}$ & $\begin{array}{c}E_{1}(0,0) \\
E_{2}(1,0) \\
E_{3}(0,1) \\
E_{4}(1,1) \\
E_{5}\left(x_{*}, y_{*}\right)\end{array}$ & $\begin{array}{l}+ \\
+ \\
- \\
+ \\
\Delta\end{array}$ & $\begin{array}{l}- \\
+ \\
-\end{array}$ & $\begin{array}{c}\text { ESS } \\
\text { Instability point } \\
\text { Saddle point } \\
\text { ESS }\end{array}$ \\
\hline 7 & Figure 1(e) & $\begin{array}{c}V<\beta C, V<(1-\beta) C \\
(1-\beta) C<(1-\alpha) P+F \\
\beta C>\alpha P+F, F<(1-\beta) C\end{array}$ & $\begin{array}{c}E_{1}(0,0) \\
E_{2}(1,0) \\
E_{3}(0,1) \\
E_{4}(1,1) \\
E_{5}\left(x_{*}, y_{*}\right)\end{array}$ & $\begin{array}{l}+ \\
+ \\
- \\
- \\
\Delta\end{array}$ & $\begin{array}{l}- \\
+\end{array}$ & $\begin{array}{c}\text { ESS } \\
\text { Instability point } \\
\text { Saddle point } \\
\text { Saddle point } \\
\text { ESS }\end{array}$ \\
\hline 8 & Figure $1(\mathrm{f})$ & $\begin{array}{c}V<\beta C, V<(1-\beta) C \\
(1-\beta) C<(1-\alpha) P+F \\
\beta C>\alpha P+F, F>(1-\beta) C\end{array}$ & $\begin{array}{c}E_{1}(0,0) \\
E_{2}(1,0) \\
E_{3}(0,1) \\
E_{4}(1,1) \\
E_{5}\left(x_{*}, y_{*}\right)\end{array}$ & $\begin{array}{l}+ \\
+ \\
+ \\
- \\
\Delta\end{array}$ & $\begin{array}{l}- \\
+ \\
+\end{array}$ & $\begin{array}{c}\text { ESS } \\
\text { Instability point } \\
\text { ESS } \\
\text { Saddle point }\end{array}$ \\
\hline
\end{tabular}

Note. \# = the constraints conflict with each other.

low. Affected by the additional profit $P$, two ESSs emerge, $E_{2}(0,0)$ and $E_{4}(1,1)$. So, the players will choose cooperation or non-cooperation strategies according to the additional profit.

(5) In Category $1.5,(1-\beta) C<(1-\alpha) P+F$, $\beta C>\alpha P+F$, and $F<(1-\beta) C$. For the manufacturers, the cost of sharing information is high; however, for the logistics service providers, this cost, the subsidy, and the penalty of adopting the non-cooperation strategy are low. An ESS exists, $E_{2}(0,1)$.

(6) In Category 1.6, $(1-\beta) C<(1-\alpha) P+F$, $\beta C>\alpha P+F$, and $F>(1-\beta) C$. Comparing with (5), the penalty cost increases, resulting in two ESSs, $E_{1}(0,0)$ and $E_{3}(0,1)$.
(2) Category 2: $V<\beta C$ and $V>(1-\beta) C$

(1) In Category 2.1, $(1-\beta) C>(1-\alpha) P+F$, $\beta C<\alpha P+F$, and $F<(1-\beta) C$. Here, the subsidy to the manufacturers is low, and the cost of sharing information is also low. However, the subsidy to the logistics service providers is high as well as the cost of sharing information. When the penalty of non-cooperation is also low, both players behave by waiting and following the other ones. So, no ESS exists.

(2) In Category 2.2, $(1-\beta) C>(1-\alpha) P+F$, $\beta C>\alpha P+F$, and $F<(1-\beta) C$. The logistics service providers can get a high subsidy that is higher than the cost of sharing information. So, they will choose the cooperation strategy. 
TABLe 7: Local stability analysis $V<\beta C$ and $V>(1-\beta) C$.

\begin{tabular}{|c|c|c|c|c|c|c|}
\hline No. & Figure & Constraints & EP & $\operatorname{det} J$ & $\operatorname{tr} J$ & State \\
\hline 1 & Figure 2(a) & $\begin{array}{c}V<\beta C, V>(1-\beta) C \\
(1-\beta) C>(1-\alpha) P+F \\
\beta C<\alpha P+F, F<(1-\beta) C\end{array}$ & $\begin{array}{c}E_{1}(0,0) \\
E_{2}(1,0) \\
E_{3}(0,1) \\
E_{4}(1,1) \\
E_{5}\left(x_{*}, y_{*}\right)\end{array}$ & $\begin{array}{l}- \\
- \\
+ \\
- \\
\Delta\end{array}$ & $\begin{array}{l}+ \\
0\end{array}$ & $\begin{array}{l}\text { Saddle point } \\
\text { Saddle point } \\
\text { Instability point } \\
\text { Saddle point }\end{array}$ \\
\hline $2 \#$ & & $\begin{array}{c}V<\beta C, V>(1-\beta) C \\
(1-\beta) C>(1-\alpha) P+F \\
\beta C<\alpha P+F, F>(1-\beta) C\end{array}$ & $\begin{array}{c}E_{1}(0,0) \\
E_{2}(1,0) \\
E_{3}(0,1) \\
E_{4}(1,1) \\
E_{5}\left(x_{*}, y_{*}\right)\end{array}$ & $\begin{array}{l}- \\
- \\
- \\
- \\
\Delta\end{array}$ & 0 & $\begin{array}{l}\text { Saddle point } \\
\text { Saddle point } \\
\text { Saddle point } \\
\text { Saddle point }\end{array}$ \\
\hline 3 & Figure 2(b) & $\begin{array}{c}V<\beta C, V>(1-\beta) C \\
(1-\beta) C>(1-\alpha) P+F \\
\beta C>\alpha P+F, F<(1-\beta) C\end{array}$ & $\begin{array}{c}E_{1}(0,0) \\
E_{2}(1,0) \\
E_{3}(0,1) \\
E_{4}(1,1) \\
E_{5}\left(x_{*}, y_{*}\right) \\
\end{array}$ & $\begin{array}{l}- \\
- \\
- \\
+ \\
\Delta\end{array}$ & $\begin{array}{l}+ \\
0 \\
\end{array}$ & $\begin{array}{c}\text { Saddle point } \\
\text { Saddle point } \\
\text { Saddle point } \\
\text { Instability point }\end{array}$ \\
\hline $4 \#$ & & $\begin{array}{c}V<\beta C, V>(1-\beta) C \\
(1-\beta) C>(1-\alpha) P+F \\
\beta C>\alpha P+F, F>(1-\beta) C\end{array}$ & $\begin{array}{c}E_{1}(0,0) \\
E_{2}(1,0) \\
E_{3}(0,1) \\
E_{4}(1,1) \\
E_{5}\left(x_{*}, y_{*}\right)\end{array}$ & $\begin{array}{l}- \\
- \\
+ \\
+ \\
\Delta\end{array}$ & $\begin{array}{l}- \\
+ \\
0\end{array}$ & $\begin{array}{l}\text { Saddle point } \\
\text { Saddle point } \\
\text { ESS } \\
\text { Instability point }\end{array}$ \\
\hline 5 & Figure 2(c) & $\begin{array}{c}V<\beta C, V>(1-\beta) C \\
(1-\beta) C<(1-\alpha) P+F \\
\beta C<\alpha P+F, F<(1-\beta) C\end{array}$ & $\begin{array}{c}E_{1}(0,0) \\
E_{2}(1,0) \\
E_{3}(0,1) \\
E_{4}(1,1) \\
E_{5}\left(x_{*}, y_{*}\right) \\
\end{array}$ & $\begin{array}{l}- \\
+ \\
+ \\
+ \\
\Delta\end{array}$ & $\begin{array}{l}+ \\
+ \\
- \\
0\end{array}$ & $\begin{array}{c}\text { Saddle point } \\
\text { Instability point } \\
\text { Instability point } \\
\text { ESS }\end{array}$ \\
\hline 6 & Figure 2(d) & $\begin{array}{c}\mathrm{V}<\beta C, \mathrm{~V}>(1-\beta) \mathrm{C} \\
(1-\beta) C<(1-\alpha) P+F \\
\beta C<\alpha P+F, F>(1-\beta) C\end{array}$ & $\begin{array}{c}E_{1}(0,0) \\
E_{2}(1,0) \\
E_{3}(0,1) \\
E_{4}(1,1) \\
E_{5}\left(x_{*}, y_{*}\right)\end{array}$ & $\begin{array}{l}- \\
+ \\
- \\
+ \\
\Delta\end{array}$ & $\begin{array}{c}+ \\
- \\
0\end{array}$ & $\begin{array}{l}\text { Saddle point } \\
\text { Instability point } \\
\text { Saddle point } \\
\text { ESS }\end{array}$ \\
\hline 7 & Figure 2(e) & $\begin{array}{c}V<\beta C, V>(1-\beta) C \\
(1-\beta) C<(1-\alpha) P+F \\
\beta C>\alpha P+F, F<(1-\beta) C\end{array}$ & $\begin{array}{c}E_{1}(0,0) \\
E_{2}(1,0) \\
E_{3}(0,1) \\
E_{4}(1,1) \\
E_{5}\left(x_{*}, y_{*}\right) \\
\end{array}$ & $\begin{array}{l}- \\
+ \\
- \\
- \\
\Delta\end{array}$ & + & $\begin{array}{l}\text { Saddle point } \\
\text { Instability point } \\
\text { Saddle point } \\
\text { Saddle point }\end{array}$ \\
\hline 8 & Figure 2(f) & $\begin{array}{c}V<\beta C, V>(1-\beta) C \\
(1-\beta) C<(1-\alpha) P+F \\
\beta C>\alpha P+F, F>(1-\beta) C\end{array}$ & $\begin{array}{c}E_{1}(0,0) \\
E_{2}(1,0) \\
E_{3}(0,1) \\
E_{4}(1,1) \\
E_{5}\left(x_{*}, y_{*}\right)\end{array}$ & $\begin{array}{l}- \\
+ \\
+ \\
- \\
\Delta\end{array}$ & $\begin{array}{l}+ \\
- \\
0\end{array}$ & $\begin{array}{c}\text { Saddle point } \\
\text { Instability point } \\
\text { ESS } \\
\text { Saddle point }\end{array}$ \\
\hline
\end{tabular}

Note. \# = the constraints conflict with each other.

However, to the manufacturers, the subsidy is lower than the cost of sharing information; the cost of sharing information is even less than the sum of the additional profit of sharing information and the penalty paid by the logistics service providers. So, the manufacturers will not choose the cooperation strategy.

(3) In Category 2.3, $(1-\beta) C<(1-\alpha) P+F$, $\beta C<\alpha P+F$, and $F<(1-\beta) C$. The cost of sharing information to the manufacturers is low; the additional profits of sharing information are all high for the two players. So, the manufacturers and logistics service providers will both choose the cooperation strategy. An ESS exists, $E_{4}(1,1)$.
(4) In Category 2.4, $(1-\beta) C<(1-\alpha) P+F$, $\beta C<\alpha P+F$, and $F>(1-\beta) C$. The penalty cost of the non-cooperation strategy is at a high level. If both players do not adopt the cooperation strategy, the penalty costs will decrease their profit. So, they will choose to adopt the cooperation strategy.

(5) In Category 2.5, $(1-\beta) C<(1-\alpha) P+F$, $\beta C>\alpha P+F$, and $F<(1-\beta) C$. The subsidy to the logistics service providers is higher and more significant than the penalty of non-cooperation strategy; the cost of sharing information and the additional profit of sharing information are both low. Therefore, they both will not adopt the cooperation strategy, and so no ESS exists. 
TABLE 8: Local stability analysis $V>\beta C$ and $V>(1-\beta) C$.

\begin{tabular}{|c|c|c|c|c|c|c|}
\hline No. & Figure & Constraints & EP & $\operatorname{det} J$ & $\operatorname{tr} J$ & State \\
\hline 1 & Figure $3(\mathrm{a})$ & $\begin{array}{c}V>\beta C, V>(1-\beta) C \\
(1-\beta) C>(1-\alpha) P+F \\
\beta C<\alpha P+F, F<(1-\beta) C\end{array}$ & $\begin{array}{c}E_{1}(0,0) \\
E_{2}(1,0) \\
E_{3}(0,1) \\
E_{4}(1,1) \\
E_{5}\left(x_{*}, y_{*}\right)\end{array}$ & $\begin{array}{l}+ \\
+ \\
+ \\
- \\
\Delta\end{array}$ & $\begin{array}{l}+ \\
- \\
+ \\
0\end{array}$ & $\begin{array}{l}\text { Instability point } \\
\text { ESS } \\
\text { Instability point } \\
\text { Saddle point }\end{array}$ \\
\hline $2 \#$ & & $\begin{array}{c}V>\beta C, V>(1-\beta) C \\
(1-\beta) C>(1-\alpha) P+F \\
\beta C<\alpha P+F, F>(1-\beta) C\end{array}$ & $\begin{array}{c}E_{1}(0,0) \\
E_{2}(1,0) \\
E_{3}(0,1) \\
E_{4}(1,1) \\
E_{5}\left(x_{*}, y_{*}\right)\end{array}$ & $\begin{array}{l}+ \\
+ \\
- \\
- \\
\Delta\end{array}$ & $\begin{array}{l}+ \\
+ \\
-\end{array}$ & $\begin{array}{c}\text { Instability point } \\
\text { ESS } \\
\text { Saddle point } \\
\text { Saddle point }\end{array}$ \\
\hline 3 & Figure 3(b) & $\begin{array}{c}V>\beta C, V>(1-\beta) C \\
(1-\beta) C>(1-\alpha) P+F \\
\beta C>\alpha P+F, F<(1-\beta) C\end{array}$ & $\begin{array}{c}E_{1}(0,0) \\
E_{2}(1,0) \\
E_{3}(0,1) \\
E_{4}(1,1) \\
E_{5}\left(x_{*}, y_{*}\right)\end{array}$ & $\begin{array}{l}+ \\
+ \\
- \\
+ \\
\Delta\end{array}$ & $\begin{array}{l}+ \\
- \\
+ \\
+\end{array}$ & $\begin{array}{c}\text { Instability point } \\
\text { ESS } \\
\text { Saddle point } \\
\text { Instability point }\end{array}$ \\
\hline $4 \#$ & & $\begin{array}{c}V>\beta C, V>(1-\beta) C \\
(1-\beta) C>(1-\alpha) P+F \\
\beta C>\alpha P+F, F>(1-\beta) C\end{array}$ & $\begin{array}{c}E_{1}(0,0) \\
E_{2}(1,0) \\
E_{3}(0,1) \\
E_{4}(1,1) \\
E_{5}\left(x_{*}, y_{*}\right)\end{array}$ & $\begin{array}{l}+ \\
+ \\
+ \\
+ \\
\Delta\end{array}$ & $\begin{array}{l}+ \\
- \\
- \\
+ \\
0\end{array}$ & $\begin{array}{l}\text { Instability point } \\
\text { ESS } \\
\text { ESS } \\
\text { Instability point }\end{array}$ \\
\hline 5 & Figure $3(\mathrm{c})$ & $\begin{array}{c}V>\beta C, V>(1-\beta) C \\
(1-\beta) C<(1-\alpha) P+F \\
\beta C<\alpha P+F, F<(1-\beta) C\end{array}$ & $\begin{array}{c}E_{1}(0,0) \\
E_{2}(1,0) \\
E_{3}(0,1) \\
E_{4}(1,1) \\
E_{5}\left(x_{*}, y_{*}\right)\end{array}$ & $\begin{array}{l}+ \\
- \\
+ \\
+ \\
\Delta\end{array}$ & $\begin{array}{l}+ \\
- \\
0\end{array}$ & $\begin{array}{l}\text { Instability point } \\
\text { Saddle point } \\
\text { Instability point } \\
\text { ESS }\end{array}$ \\
\hline 6 & Figure $3(\mathrm{~d})$ & $\begin{array}{c}V>\beta C, V>(1-\beta) C \\
(1-\beta) C<(1-\alpha) P+F \\
\beta C<\alpha P+F, F>(1-\beta) C\end{array}$ & $\begin{array}{c}E_{1}(0,0) \\
E_{2}(1,0) \\
E_{3}(0,1) \\
E_{4}(1,1) \\
E_{5}\left(x_{*}, y_{*}\right)\end{array}$ & $\begin{array}{l}+ \\
- \\
- \\
+ \\
\Delta\end{array}$ & - & $\begin{array}{c}\text { Instability point } \\
\text { Saddle point } \\
\text { Saddle point } \\
\text { ESS }\end{array}$ \\
\hline 7 & Figure 3(e) & $\begin{array}{c}V>\beta C, V>(1-\beta) C \\
(1-\beta) C<(1-\alpha) P+F \\
\beta C>\alpha P+F, F<(1-\beta) C\end{array}$ & $\begin{array}{c}E_{1}(0,0) \\
E_{2}(1,0) \\
E_{3}(0,1) \\
E_{4}(1,1) \\
E_{5}\left(x_{*}, y_{*}\right)\end{array}$ & $\begin{array}{l}+ \\
- \\
- \\
- \\
\Delta\end{array}$ & + & $\begin{array}{l}\text { Instability point } \\
\text { Saddle point } \\
\text { Saddle point } \\
\text { Saddle point }\end{array}$ \\
\hline 8 & Figure 3(f) & $\begin{array}{c}V>\beta C, V>(1-\beta) C \\
(1-\beta) C<(1-\alpha) P+F \\
\beta C>\alpha P+F, F>(1-\beta) C\end{array}$ & $\begin{array}{c}E_{1}(0,0) \\
E_{2}(1,0) \\
E_{3}(0,1) \\
E_{4}(1,1) \\
E_{5}\left(x_{*}, y_{*}\right)\end{array}$ & $\begin{array}{l}+ \\
- \\
+ \\
- \\
\Delta\end{array}$ & - & $\begin{array}{c}\text { Instability point } \\
\text { Saddle point } \\
\text { ESS } \\
\text { Saddle point }\end{array}$ \\
\hline
\end{tabular}

Note. \# = the constraints conflict with each other.

(6) In Category 2.6, $(1-\beta) C<(1-\alpha) P+F$, $\beta C>\alpha P+F$, and $F>(1-\beta) C$. The penalty of non-cooperation strategy increases. So, the logistics service providers adopting the cooperation strategy will obtain higher profit from the penalty when the manufacturers adopt the noncooperation strategy. To the manufacturers, the subsidy cannot compensate for the cost of sharing information. So, an ESS exists, $E_{2}(0,1)$.

(3) Category 3: $V>\beta C$ and $V>(1-\beta) C$

(1) In Category 3.1, $(1-\beta) C>(1-\alpha) P+F$, $\beta C<\alpha P+F$, and $F<(1-\beta) C$. To the logistics service providers, the subsidy of sharing information is high and even higher than the cost of sharing information. The evolutionary tendency depends on the additional profit of sharing information. There exists an ESS, $E_{2}(1,0)$.

(2) In Category 3.2, $(1-\beta) C>(1-\alpha) P+F$, $\beta C>\alpha P+F$, and $F<(1-\beta) C$. Similarly, an ESS, $E_{2}(1,0)$ exists.

(3) In Category 3.3, $(1-\beta) C<(1-\alpha) P+F$, $\beta C<\alpha P+F$, and $F<(1-\beta) C$. The subsidy is higher than the cost of sharing information; this cost of sharing information is low; simultaneously, the subsidy and additional profit of sharing information are high; and the penalty cost of the non-cooperation strategy is low. So, for the manufacturers and logistics service providers, adopting the cooperation strategy will increase the total profit. So, the ESS is $E_{4}(1,1)$. 
TABLe 9: Local stability analysis $V>\beta C$ and $V<(1-\beta) C$.

\begin{tabular}{|c|c|c|c|c|c|c|}
\hline No. & Figure & Constraints & EP & $\operatorname{det} J$ & $\operatorname{tr} J$ & State \\
\hline 1 & Figure 4(a) & $\begin{array}{c}V>\beta C, V<(1-\beta) C \\
(1-\beta) C>(1-\alpha) P+F \\
\beta C<\alpha P+F, F<(1-\beta) C\end{array}$ & $\begin{array}{c}E_{1}(0,0) \\
E_{2}(1,0) \\
E_{3}(0,1) \\
E_{4}(1,1) \\
E_{5}\left(x_{*}, y_{*}\right)\end{array}$ & $\begin{array}{l}- \\
+ \\
+ \\
- \\
\Delta\end{array}$ & $\begin{array}{l}- \\
+ \\
0\end{array}$ & $\begin{array}{l}\text { Saddle point } \\
\text { ESS } \\
\text { Instability point } \\
\text { Saddle point }\end{array}$ \\
\hline $2 \#$ & & $\begin{array}{c}V>\beta C, V<(1-\beta) C \\
(1-\beta) C>(1-\alpha) P+F \\
\beta C<\alpha P+F, F>(1-\beta) C\end{array}$ & $\begin{array}{c}E_{1}(0,0) \\
E_{2}(1,0) \\
E_{3}(0,1) \\
E_{4}(1,1) \\
E_{5}\left(x_{*}, y_{*}\right)\end{array}$ & $\begin{array}{l}- \\
+ \\
- \\
- \\
\Delta\end{array}$ & $\begin{array}{l}- \\
0\end{array}$ & $\begin{array}{l}\text { Saddle point } \\
\text { ESS } \\
\text { Saddle point } \\
\text { Saddle point }\end{array}$ \\
\hline 3 & Figure 4(b) & $\begin{array}{c}V>\beta C, V<(1-\beta) C \\
(1-\beta) C>(1-\alpha) P+F \\
\beta C>\alpha P+F, F<(1-\beta) C\end{array}$ & $\begin{array}{c}E_{1}(0,0) \\
E_{2}(1,0) \\
E_{3}(0,1) \\
E_{4}(1,1) \\
E_{5}\left(x_{*}, y_{*}\right)\end{array}$ & $\begin{array}{l}- \\
+ \\
- \\
+ \\
\Delta\end{array}$ & $\begin{array}{l}- \\
+ \\
0\end{array}$ & $\begin{array}{c}\text { Saddle point } \\
\text { ESS } \\
\text { Saddle point } \\
\text { Instability point }\end{array}$ \\
\hline 4\# & & $\begin{array}{c}V>\beta C, V<(1-\beta) C \\
(1-\beta) C>(1-\alpha) P+F \\
\beta C>\alpha P+F, F>(1-\beta) C\end{array}$ & $\begin{array}{c}E_{1}(0,0) \\
E_{2}(1,0) \\
E_{3}(0,1) \\
E_{4}(1,1) \\
E_{5}\left(x_{*}, y_{*}\right)\end{array}$ & $\begin{array}{l}- \\
+ \\
+ \\
+ \\
\Delta\end{array}$ & $\begin{array}{l}- \\
- \\
+ \\
0\end{array}$ & $\begin{array}{c}\text { Saddle point } \\
\text { ESS } \\
\text { ESS } \\
\text { Instability point }\end{array}$ \\
\hline 5 & Figure 4(c) & $\begin{array}{c}V>\beta C, V<(1-\beta) C \\
(1-\beta) C<(1-\alpha) P+F \\
\beta C<\alpha P+F, F<(1-\beta) C\end{array}$ & $\begin{array}{c}E_{1}(0,0) \\
E_{2}(1,0) \\
E_{3}(0,1) \\
E_{4}(1,1) \\
E_{5}\left(x_{*}, y_{*}\right)\end{array}$ & $\begin{array}{l}- \\
- \\
+ \\
+ \\
\Delta\end{array}$ & $\begin{array}{l}+ \\
- \\
0\end{array}$ & $\begin{array}{l}\text { Saddle point } \\
\text { Saddle point } \\
\text { Instability point } \\
\text { ESS }\end{array}$ \\
\hline 6 & Figure $4(\mathrm{~d})$ & $\begin{array}{c}V>\beta C, V<(1-\beta) C \\
(1-\beta) C<(1-\alpha) P+F \\
\beta C<\alpha P+F, F>(1-\beta) C\end{array}$ & $\begin{array}{c}E_{1}(0,0) \\
E_{2}(1,0) \\
E_{3}(0,1) \\
E_{4}(1,1) \\
E_{5}\left(x_{*}, y_{*}\right)\end{array}$ & $\begin{array}{l}- \\
- \\
- \\
+ \\
\Delta\end{array}$ & - & $\begin{array}{l}\text { Saddle point } \\
\text { Saddle point } \\
\text { Saddle point } \\
\quad \text { ESS }\end{array}$ \\
\hline 7 & Figure 4(e) & $\begin{array}{c}V>\beta C, V<(1-\beta) C \\
(1-\beta) C<(1-\alpha) P+F \\
\beta C>\alpha P+F, F<(1-\beta) C\end{array}$ & $\begin{array}{c}E_{1}(0,0) \\
E_{2}(1,0) \\
E_{3}(0,1) \\
E_{4}(1,1) \\
E_{5}\left(x_{*}, y_{*}\right)\end{array}$ & $\begin{array}{l}- \\
- \\
- \\
- \\
\Delta\end{array}$ & 0 & $\begin{array}{l}\text { Saddle point } \\
\text { Saddle point } \\
\text { Saddle point } \\
\text { Saddle point }\end{array}$ \\
\hline $8 \#$ & & $\begin{array}{c}V>\beta C, V<(1-\beta) C \\
(1-\beta) C<(1-\alpha) P+F \\
\beta C>\alpha P+F, F>(1-\beta) C\end{array}$ & $\begin{array}{c}E_{1}(0,0) \\
E_{2}(1,0) \\
E_{3}(0,1) \\
E_{4}(1,1) \\
E_{5}\left(x_{*}, y_{*}\right)\end{array}$ & $\begin{array}{l}- \\
- \\
+ \\
- \\
\Delta\end{array}$ & - & $\begin{array}{c}\text { Saddle point } \\
\text { Saddle point } \\
\text { ESS } \\
\text { Saddle point }\end{array}$ \\
\hline
\end{tabular}

Note. \# = the constraints conflict with each other.

(4) In Category 3.4, $(1-\beta) C<(1-\alpha) P+F$, $\beta C<\alpha P+F$, and $F>(1-\beta) C$. Comparing with (3), the penalty of the non-cooperation strategy increases. So, for the manufacturers, adopting the cooperation strategy can avoid the penalty and obtain a high subsidy and additional profit of sharing information. The ESS is to adopt the cooperation strategy, namely, $E_{4}(1,1)$.

(5) In Category 3.5, $(1-\beta) C<(1-\alpha) P+F$, $\beta C>\alpha P+F$, and $F<(1-\beta) C$. The subsidy is high, while the additional profit of sharing information is low. No ESS exists.

(6) In Category 3.6, $(1-\beta) C<(1-\alpha) P+F$, $\beta C>\alpha P+F$, and $F>(1-\beta) C$. The additional profit of cooperation strategy drops, while the logistics service providers' additional profit increases. So, an ESS exists, $E_{3}(0,1)$.

(4) Category 4: $V>\beta C$ and $V<(1-\beta) C$

(1) In Category 4.1, $(1-\beta) C>(1-\alpha) P+F$, $\beta C<\alpha P+F$, and $F<(1-\beta) C$. To the logistics service providers, the cost of sharing information is high, while the additional profit is low. Additionally, to the manufacturers, the additional profit of sharing information is high, and the subsidy is higher than the cost of sharing information. So, to maximize the total profit, an ESS exists, $E_{2}(1,0)$.

(2) In Category 4.2, $(1-\beta) C>(1-\alpha) P+F$, $\beta C>\alpha P+F$, and $F<(1-\beta) C$. The subsidy to 
Mathematical Problems in Engineering

11

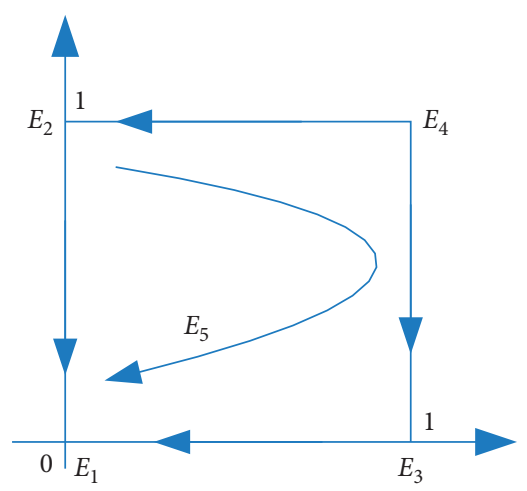

(a)

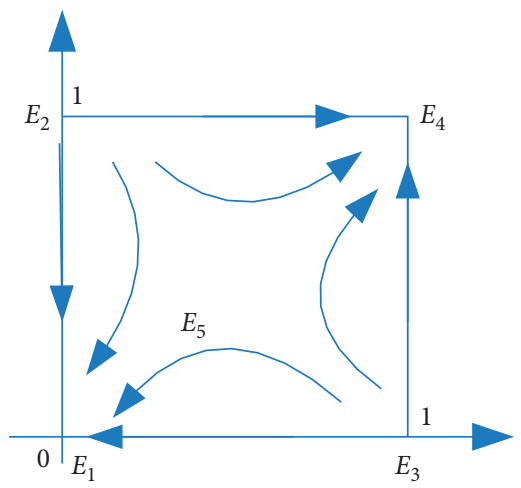

(d)

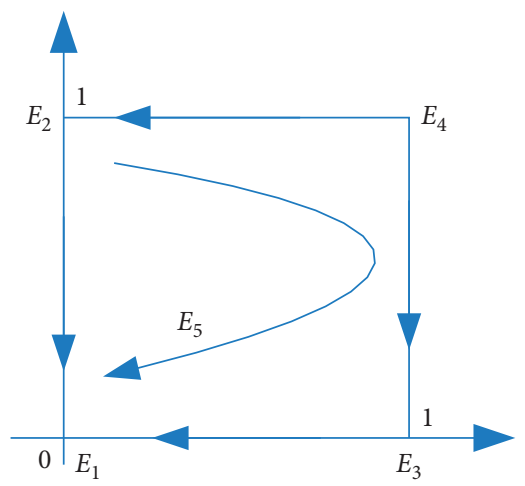

(b)

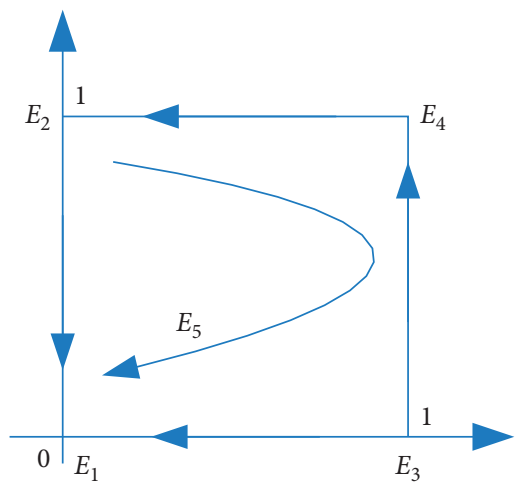

(e)

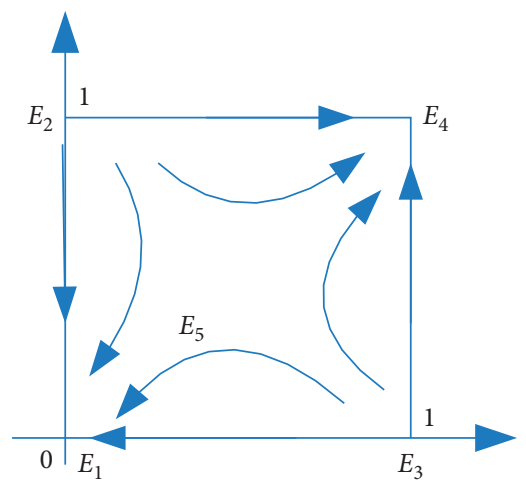

(c)

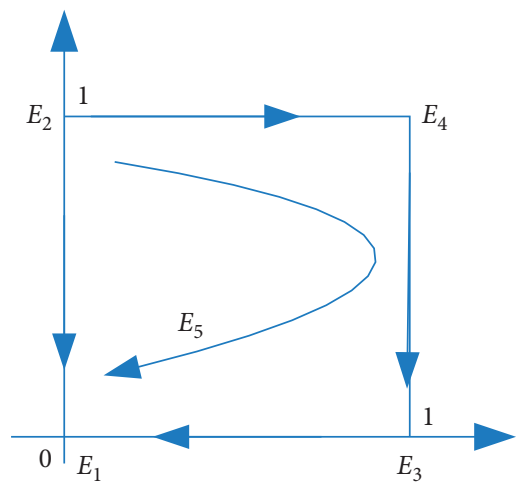

(f)

Figure 1: The local stability of the evolutionary game $V<\beta C$ and $V<(1-\beta) C$.

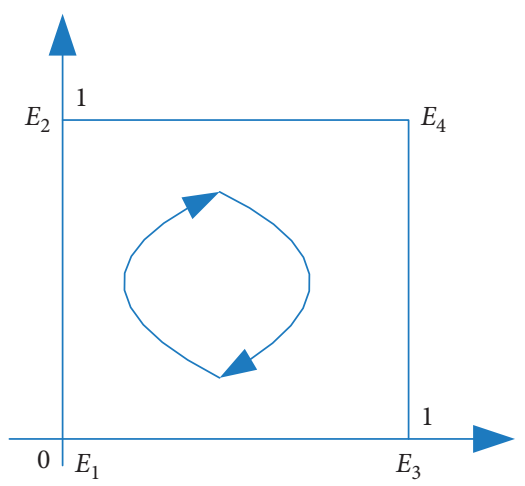

(a)

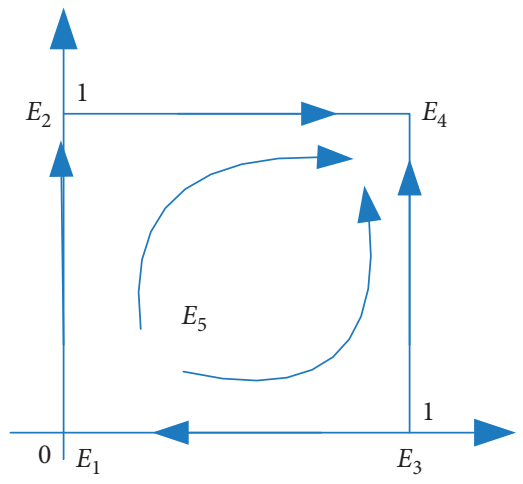

(d)

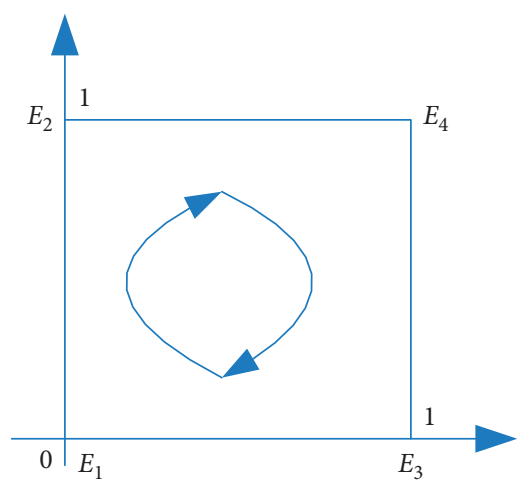

(b)

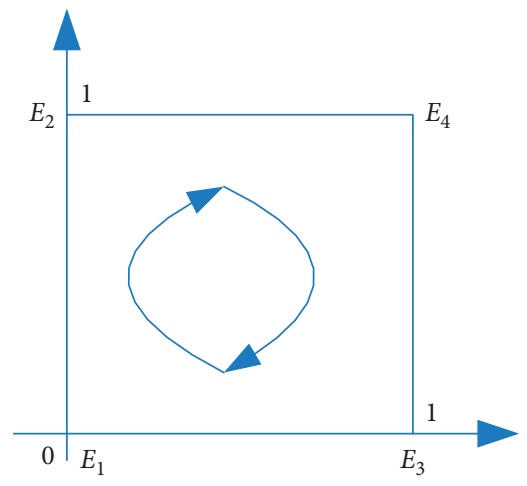

(e)

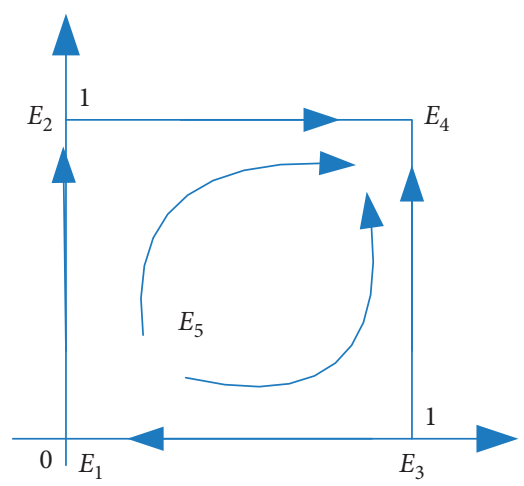

(c)

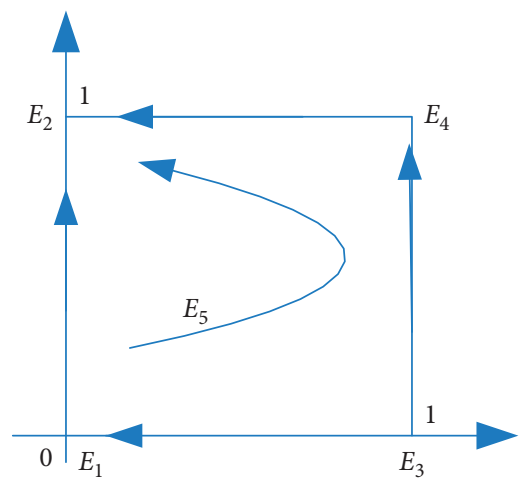

(f)

Figure 2: The local stability of the evolutionary game $V<\beta C$ and $V>(1-\beta) C$. 
12

Mathematical Problems in Engineering

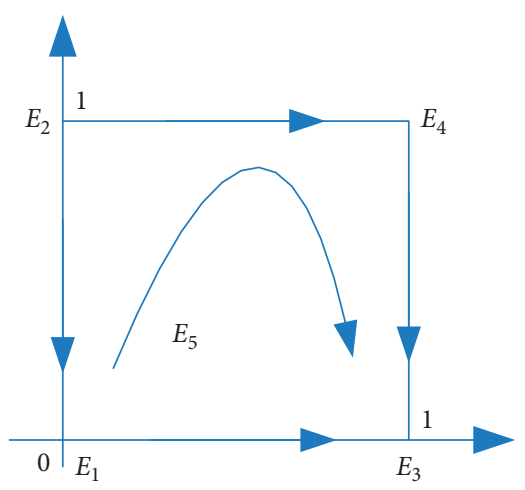

(a)

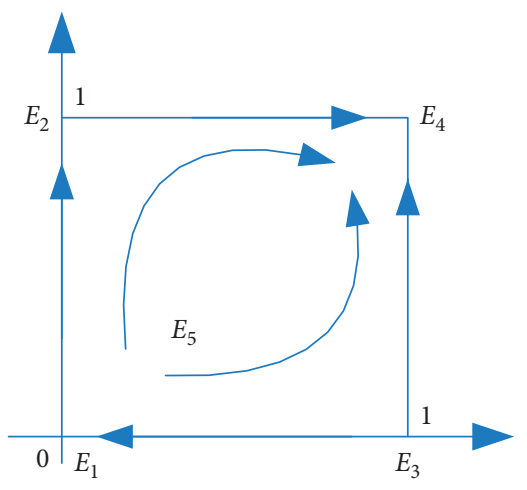

(d)

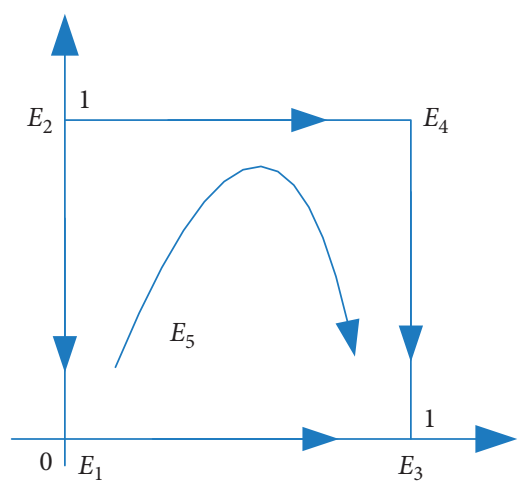

(b)

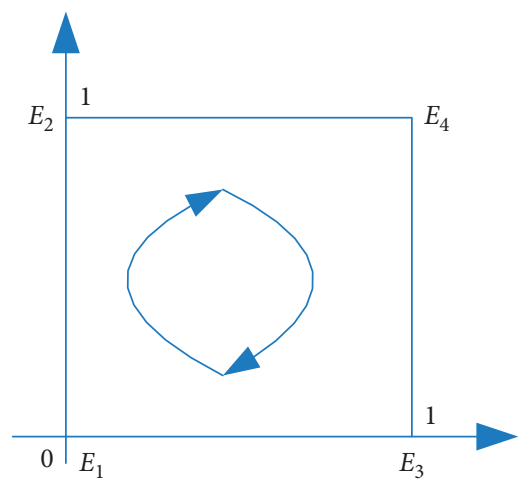

(e)

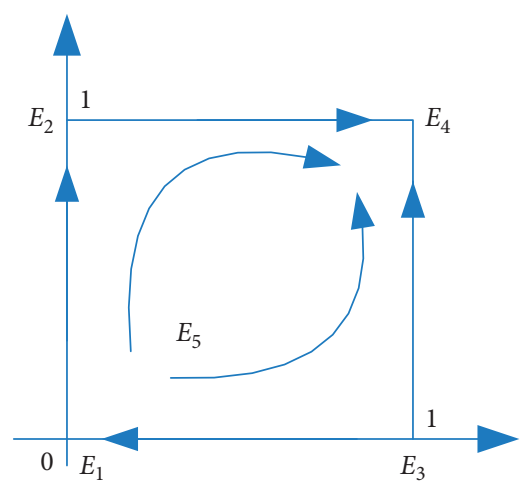

(c)

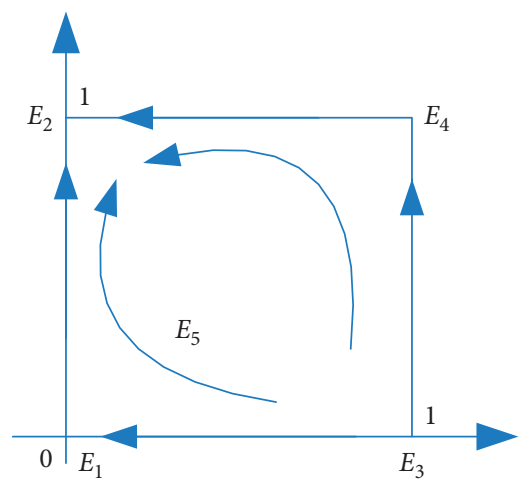

(f)

FIgURE 3: The local stability of the evolutionary game $V>\beta C$ and $V>(1-\beta) C$.

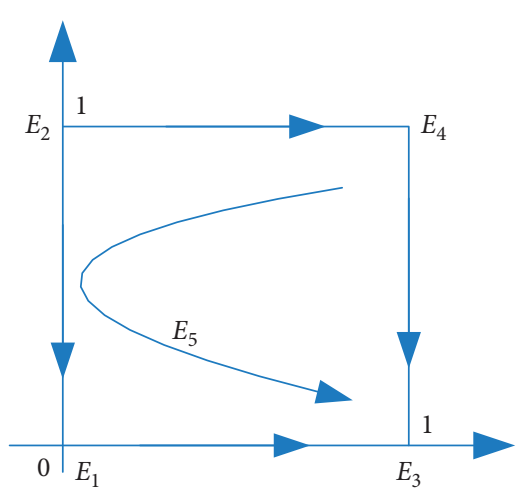

(a)

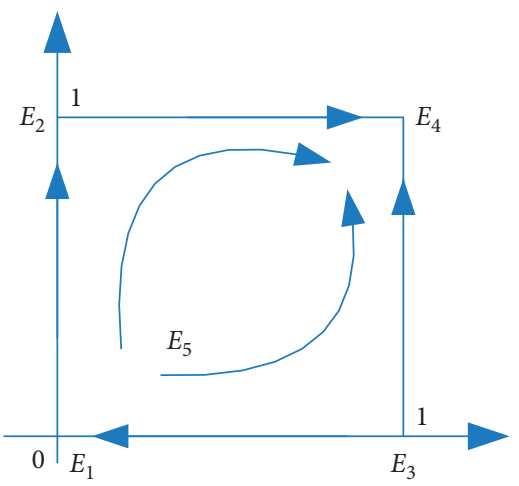

(d)

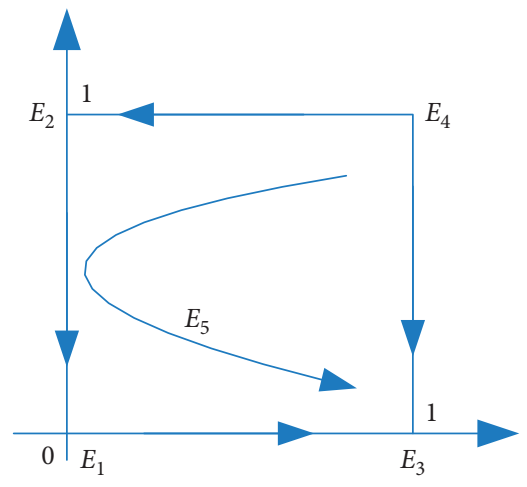

(b)

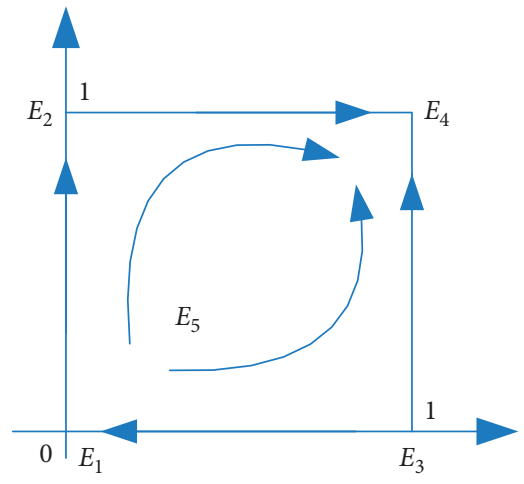

(c)

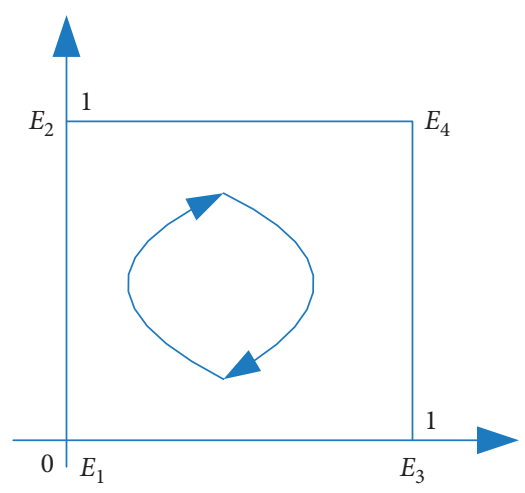

(e)

Figure 4: The local stability of the evolutionary game $V>\beta C$ and $V<(1-\beta) C$. 


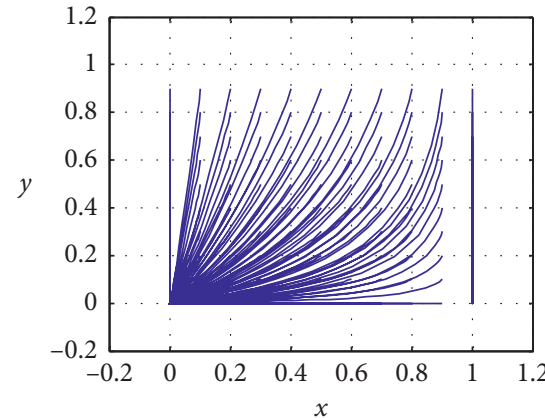

(a)

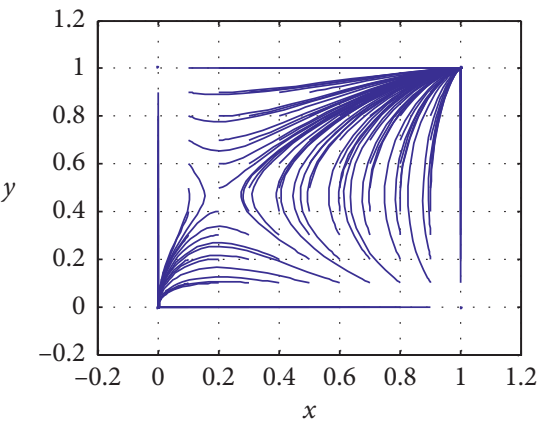

(d)

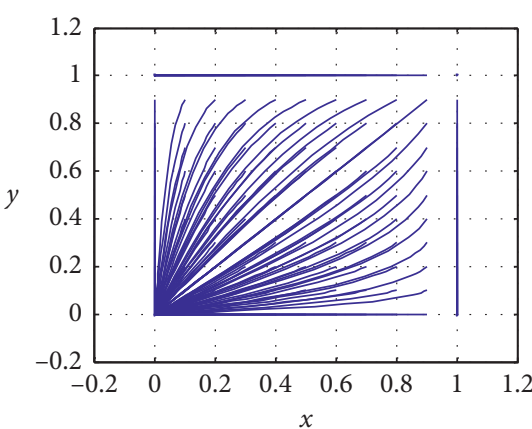

(b)

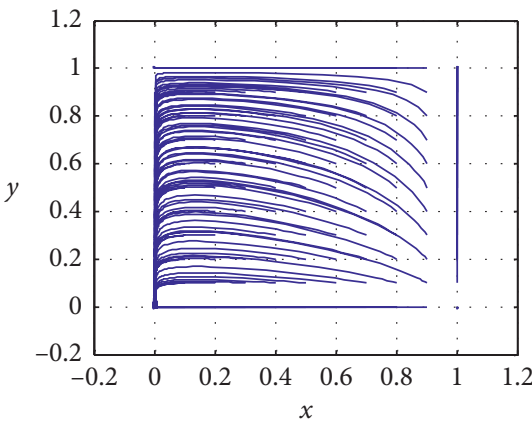

(e)

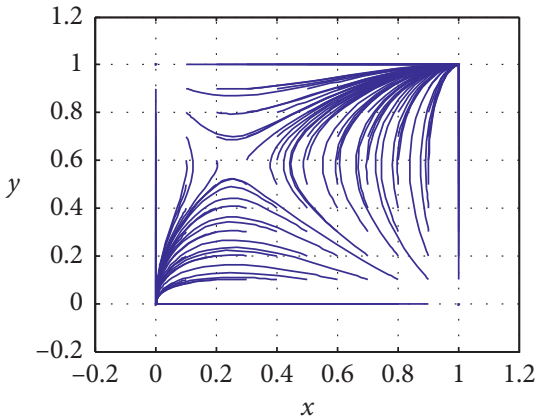

(c)

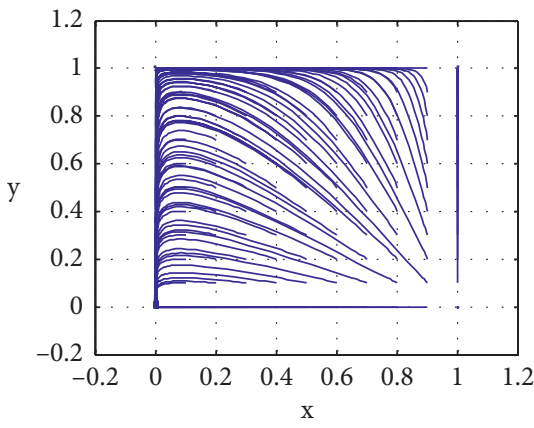

(f)

Figure 5: Evolutionary paths $V<\beta C$ and $V<(1-\beta) C$.

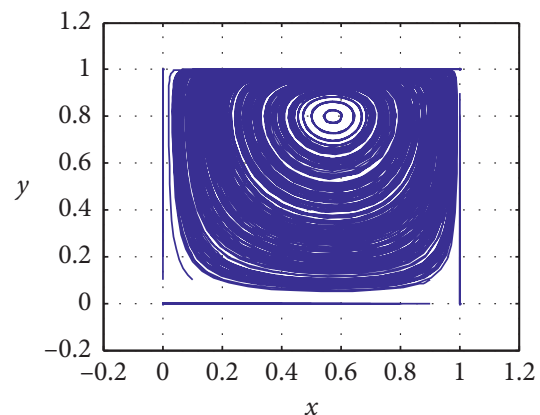

(a)

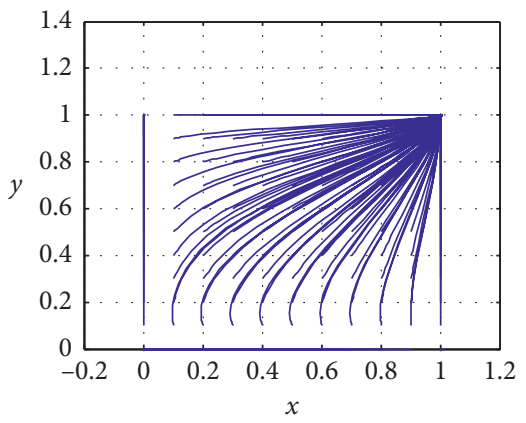

(d)

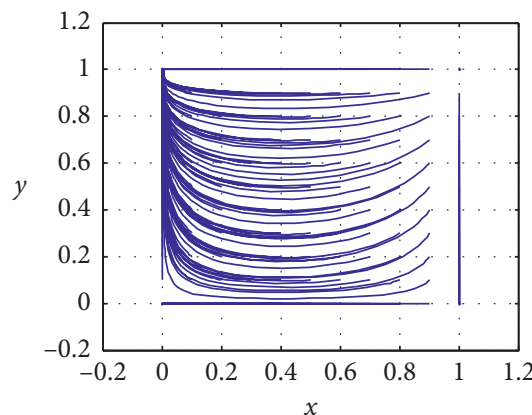

(b)

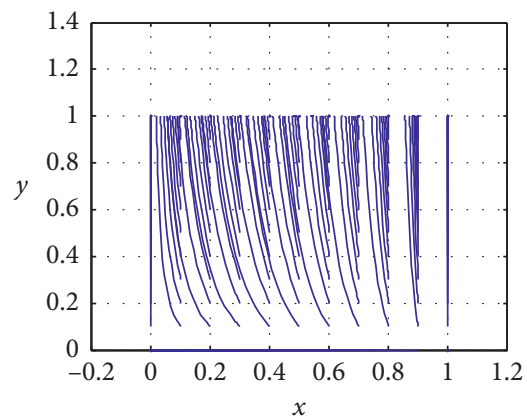

(e)

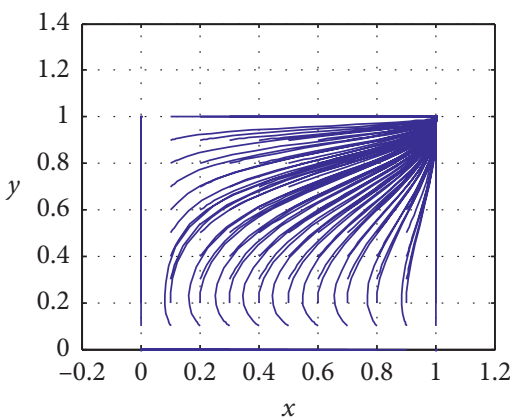

(c)

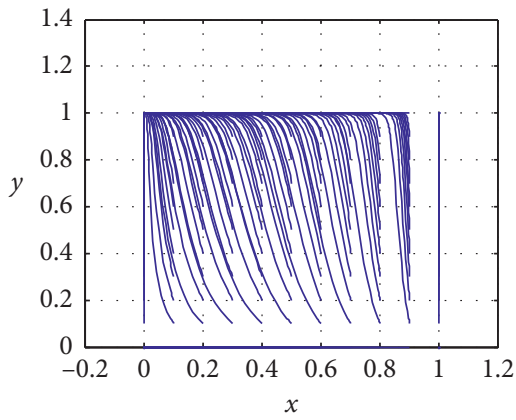

(f)

FIgURe 6: Evolutionary paths $V<\beta C$ and $V>(1-\beta) C$.

the manufacturers is higher than the cost of sharing information. However, for the logistics service providers, the subsidy is lower than the cost of sharing information, and the additional profit is also low. So, an ESS exists, $E_{2}(1,0)$. 


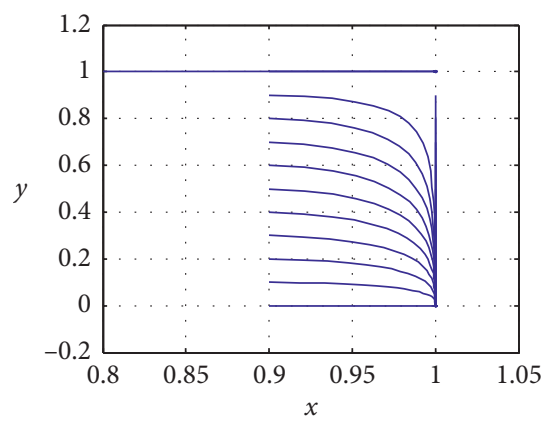

(a)

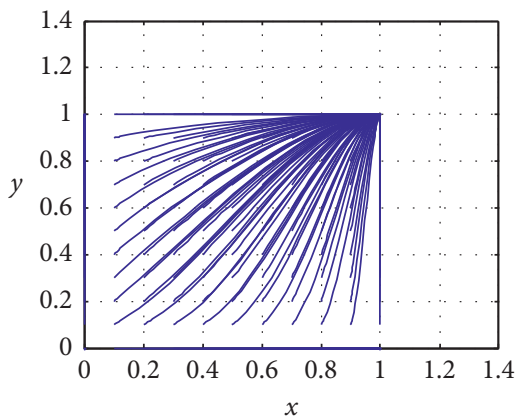

(d)

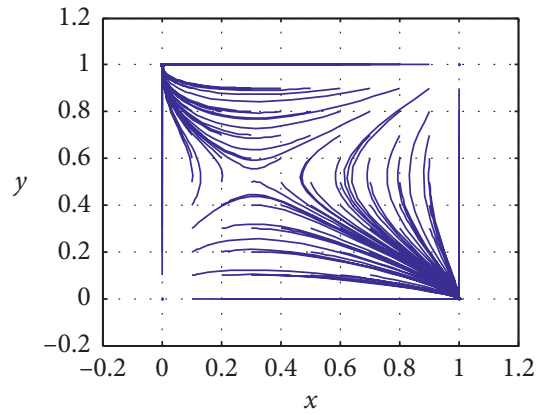

(b)

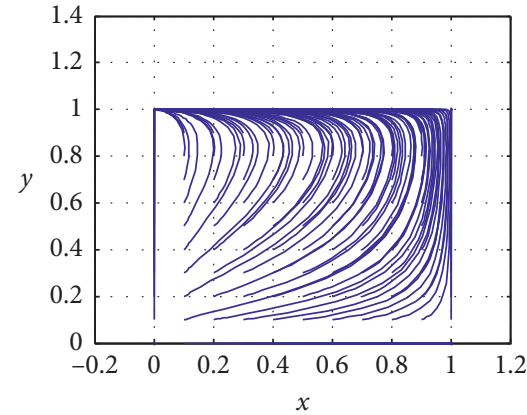

(e)

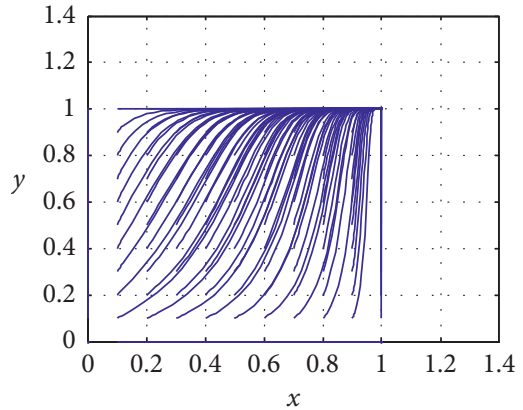

(c)

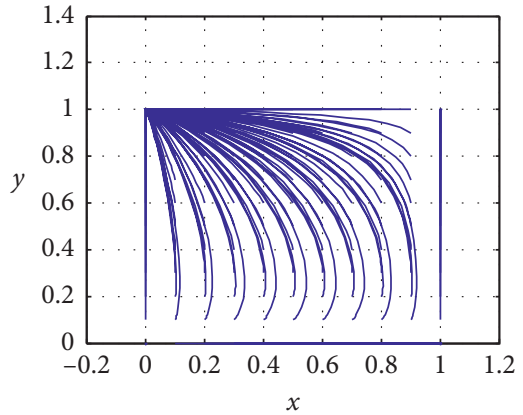

(f)

FIgURE 7: Evolutionary paths $V>\beta C$ and $V>(1-\beta) C$.

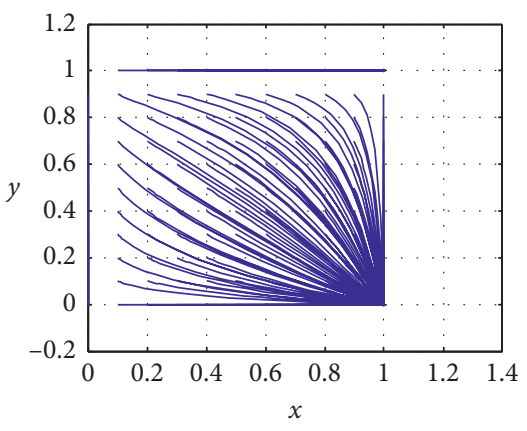

(a)

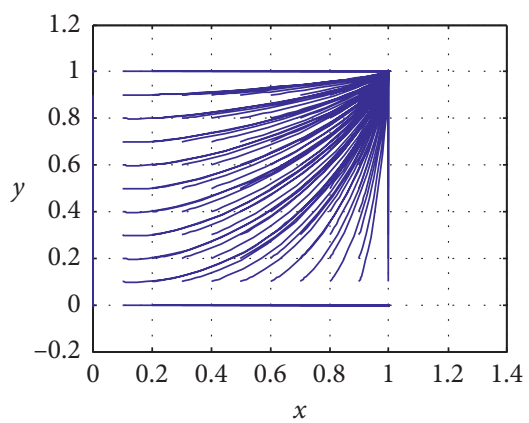

(d)

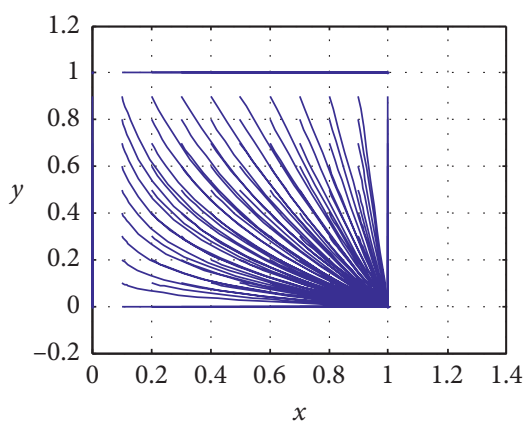

(b)

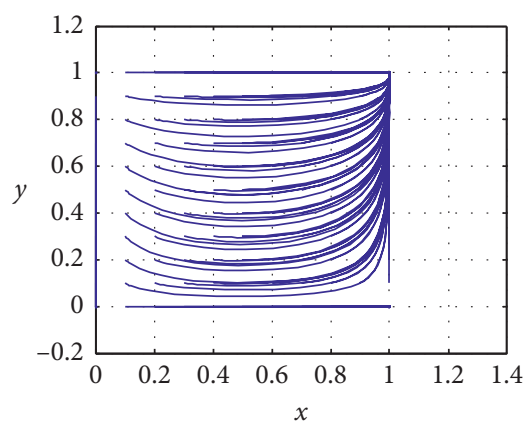

(c)

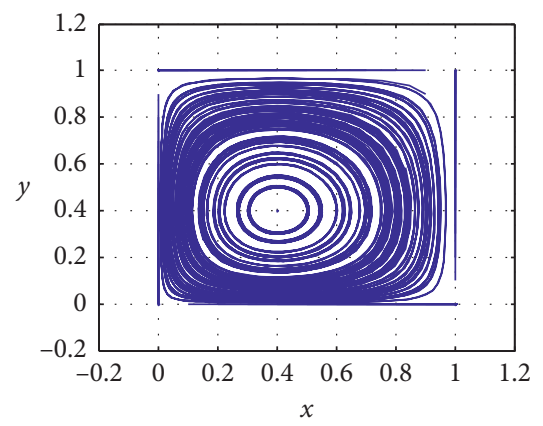

(e)

Figure 8: Evolutionary paths $V>\beta C$ and $V<(1-\beta) C$.

(3) In Category 4.3, $(1-\beta) C<(1-\alpha) P+F$, $\beta C<\alpha P+F$, and $F<(1-\beta) C$. The additional profit of sharing information increases, which benefits both players. An ESS exists, $E_{4}(1,1)$.
(4) In Category 4.4, $(1-\beta) C<(1-\alpha) P+F$, $\beta C<\alpha P+F$, and $F>(1-\beta) C$. The additional profit of sharing information and the penalty cost of non-cooperation both increase, which 
propels the manufacturers and logistics service providers to adopt the cooperation strategy. Therefore, an ESS exists, $E_{4}(1,1)$.

(5) In Category 5.5, $(1-\beta) C<(1-\alpha) P+F$, $\beta C>\alpha P+F$, and $F<(1-\beta) C$. The subsidy to the logistics service providers is low, while the subsidy to the manufacturers is high, but the additional profit of sharing information is low. Under these conditions, no ESS exists.

\section{Numerical Study}

In the developed evolutionary game model (see (1)-(14)), eight parameters are involved $\left[\pi_{A}, \pi_{B}, P, F, V, C, \alpha, \beta\right]$. In Table 10, corresponding to the ESS analysis in Section 4.4, we use four groups of settings to present different combinations of these parameters. In this study, we use Matlab 2018 to implement the models and depict the results.

\section{Discussion and Conclusion}

6.1. Discussion. In Section 4, we constructed an evolutionary game model between the cold chain manufactures and logistics service providers for studying the impacts of information transparency on safety. To demonstrate and examine the model, we devised four categories with 23 groups of parameters to represent various scenarios for numerical experiments.

Figures 5(c), 5(d), 6(c), 6(d), 7(c), 7(d), 8(c), and 8(d) depict the impacts of the constraints $(1-\beta) C<(1-\alpha) P+F$ and $\beta C<\alpha P+F$ on the ESS and simulations. The cold chain manufacturers and logistics service providers will adopt the information-sharing strategy with high probabilities. When the right parts of the two constraints increase, the profits deduced by information sharing are high, and so the stakeholders can obtain much from the strategy. The penalty to the cold chain companies plays an important role in pushing them to adopt the information-sharing strategy.

We consider the constraints $V<\beta C$ and $V<(1-\beta) C$ in the evolutionary game model. The low subsidy will result that the stakeholders give up the information sharing strategy. We produced the numerical simulation results, as presented in Figures 5(a)-5(e). The probability of giving up the information sharing strategy is high. When the governments increase the subsidies, the stakeholders will be active in adopting the information-sharing strategy. So, in the developed model, the subsidy is an essential instrument for advocating the information-sharing strategy.

The costs undertaken by the cold chain companies are harmful to them to adopt the information-sharing strategy. When the governments can subsidize these costs, the penalties are severe enough, and the companies have no choice and will adopt the information-sharing strategy. We depict the simulation results in Figures $7(\mathrm{a})-7(\mathrm{f})$ when considering the constraints $V>\beta C$ and $V>(1-\beta) C$ in the evolutionary game model. It is beneficial for the cold chains to find effective ways to reduce the costs for information sharing technology and systems. The governments should support the companies to reduce these costs by policymaking, technology innovation, and administration.

The cold chain manufacturers and logistics service providers may present different attitudes to the information sharing strategy. The cost of sharing information may be beyond the subsidy and the penalty for some stakeholders. If the stakeholders can not adopt the information-sharing strategy consistently, they will reduce the positive effects of information sharing on cold chain safety significantly. So, the policymakers should carefully consider the profit and cost allocation ratios and the subsidy amounts according to the practical situations. These considerations should contribute to the simultaneous adoption of the information sharing strategy. Alternatively, the policy may damage the positivity of sharing information. We illustrate these analysis in Figures 6(b), 6(e), 6(f), 7(b), 7(f), and Figures 8(a)-8(d). When the manufactures and logistics service providers adopt a different strategy, the evolutionary game cannot be stable with ESSs.

Besides instant costs and profits, the informationsharing strategy can add values to cold chains. Consumers can buy cold chain products when product safety is trustful. Information sharing and transparency provide a way for the public to inspect the cold chains and so contribute to increasing purchases and profits. Therefore, when the governments devote much to administrate the cold chain transparency, the cold chain industry may be productive and effective.

6.2. Conclusion. To guard the cold chain safety, the governments should advocate information transparency as a premise for the temperature-controlled cold goods supply chains. While information transparency incurs additional costs for cold chain infrastructure, communication, and information management systems, due to its contribution to cold chain safety, the contracts between the main stakeholders and the related government departments can supervise and administrate the cooperation of sharing information by subsidies and penalties. In this study, at the industrial level, the interactions between the main cold chain stakeholders (cold goods manufacturers and cold chain logistics service providers) under administration are formulated by an evolutionary game model. The ESS analysis is conducted theoretically and numerically by considering the relations among the parameters (including the additional profits of sharing information, the penalty of adopting noncooperation strategy, the subsidies paid to the players adopting the cooperation strategy, and the ratio of reallocating costs and profits between the two populations). By using different combinations of parameters, the ESS emerges or disappears. Therefore, well-developed strategies and combinations of technical parameters contribute to safe and efficient cold chains. However, in this study, the evolutionary model is static because the parameters are given and not affected by each other. In more practical conditions, the behaviors of manufacturers, logistics service providers, and governments may interact with each other, and the static parameters will present dynamics. Besides, we will try to use 
TABle 10: Parameter settings for the simulation study.

\begin{tabular}{|c|c|c|c|c|c|c|c|c|c|c|}
\hline Category & No. & $\pi_{A}$ & $\pi_{B}$ & $P$ & $F$ & $V$ & C & $\alpha$ & $\beta$ & Evo-path \\
\hline 1 & 1 & 1000 & 800 & 100 & 30 & 50 & 200 & 0.7 & 0.5 & \multirow{6}{*}{ Figure 5} \\
\hline$V<\beta C$ & 2 & 1000 & 800 & 100 & 30 & 50 & 200 & 0.5 & 0.5 & \\
\hline$V<(1-\beta) C$ & 3 & 1000 & 800 & 200 & 70 & 50 & 200 & 0.5 & 0.6 & \\
\hline \multirow[t]{3}{*}{ Table 6} & 4 & 1000 & 800 & 100 & 150 & 50 & 200 & 0.5 & 0.6 & \\
\hline & 5 & 1000 & 800 & 100 & 50 & 50 & 200 & 0.25 & 0.7 & \\
\hline & 6 & 1000 & 800 & 100 & 100 & 50 & 200 & 0.25 & 0.7 & \\
\hline 2 & 7 & 1000 & 800 & 100 & 45 & 100 & 200 & 0.8 & 0.6 & \multirow{6}{*}{ Figure 6} \\
\hline $\mathrm{V}<\beta C$ & 8 & 1000 & 800 & 50 & 50 & 100 & 200 & 0.5 & 0.55 & \\
\hline$V>(1-\beta) C$ & 9 & 1000 & 800 & 200 & 50 & 100 & 200 & 0.7 & 0.6 & \\
\hline \multirow[t]{3}{*}{ Table 7} & 10 & 1000 & 800 & 200 & 90 & 100 & 200 & 0.7 & 0.6 & \\
\hline & 11 & 1000 & 800 & 200 & 60 & 100 & 200 & 0.3 & 0.6 & \\
\hline & 12 & 1000 & 800 & 100 & 100 & 100 & 200 & 0.15 & 0.6 & \\
\hline 3 & 13 & 1000 & 800 & 100 & 50 & 150 & 200 & 0.8 & 0.6 & \multirow{6}{*}{ Figure 7} \\
\hline$V>\beta C$ & 14 & 1000 & 800 & 50 & 50 & 120 & 200 & 0.25 & 0.45 & \\
\hline$V>(1-\beta) C$ & 15 & 1000 & 800 & 200 & 50 & 120 & 200 & 0.25 & 0.45 & \\
\hline \multirow[t]{3}{*}{ Table 8} & 16 & 1000 & 800 & 200 & 150 & 120 & 200 & 0.25 & 0.45 & \\
\hline & 17 & 1000 & 800 & 70 & 70 & 120 & 200 & 0.2 & 0.45 & \\
\hline & 18 & 1000 & 800 & 50 & 70 & 120 & 200 & 0.25 & 0.55 & \\
\hline 4 & 19 & 1000 & 800 & 100 & 40 & 120 & 200 & 0.75 & 0.25 & \multirow{5}{*}{ Figure 8} \\
\hline$V>\beta C$ & 20 & 1000 & 800 & 50 & 40 & 120 & 200 & 0.25 & 0.25 & \\
\hline$V<(1-\beta) C$ & 21 & 1000 & 800 & 100 & 70 & 100 & 200 & 0.5 & 0.45 & \\
\hline \multirow[t]{2}{*}{ Table 9} & 22 & 1000 & 800 & 100 & 120 & 100 & 200 & 0.5 & 0.45 & \\
\hline & 23 & 1000 & 800 & 100 & 50 & 100 & 200 & 0.25 & 0.45 & \\
\hline
\end{tabular}

Note. evo-path $=$ evolutionary path .

dynamic, differential, and Bayesian game models to examine the dynamics between the manufacturers and logistics service providers. Different models may reveal different features of the problem. Moreover, a cold chain involves various stakeholders in the supply chain, other than just manufacturers and logistics service providers. A complicate supply chain may revise the proposed evolutionary game models and generate new research opportunities in the future. We conduct theoretical analysis in this study, while we can further improve the study by using real-world cases.

\section{Data Availability}

The data used to support the findings of this study are included within the article.

\section{Conflicts of Interest}

The authors declare that they have no conflicts of interest.

\section{Acknowledgments}

The National Natural Science Foundation of China (no. 71871136) and the Science and Technology Commission of Shanghai Municipality (no. 17DZ2280200) partially support this study financially.

\section{References}

[1] Y. Bouzembrak, M. Klüche, A. Gavai, and H. J. P. Marvin, "Internet of things in food safety: literature review and a bibliometric analysis," Trends in Food Science \& Technology, vol. 94, pp. 54-64, 2019.
[2] H.-I. Hsiao and K.-L. Huang, "Time-temperature transparency in the cold chain," Food Control, vol. 64, pp. 181-188, 2016.

[3] H. Luo, M. Zhu, S. Ye, H. Hou, Y. Chen, and L. Bulysheva, "An intelligent tracking system based on internet of things for the cold chain," Internet Research, vol. 26, no. 2, pp. 435-445, 2016.

[4] W. Chen and Z.-H. Hu, "Analysis of multi-stakeholders' behavioral strategies considering public participation under carbon taxes and subsidies: an evolutionary game approach," Sustainability, vol. 12, no. 3, p. 1023, 2020.

[5] W. Chen and Z.-H. Hu, "Using evolutionary game theory to study governments and manufacturers' behavioral strategies under various carbon taxes and subsidies," Journal of Cleaner Production, vol. 201, pp. 123-141, 2018.

[6] K. Zheng, Z. Zhang, Y. Chen, and J. Wu, "Blockchain adoption for information sharing: risk decision-making in spacecraft supply chain," Enterprise Information Systems, pp. 1-22, 2019.

[7] Z. Min, X. Mikai, and D. Debao, "Research on game strategy of information sharing in cross-border e-commerce supply chain between manufacturers and retailers," in Advances in Intelligent Systems and Computing, pp. 399-406, Springer, Berlin, Germany, 2020.

[8] H. Deng and X. Liang, "RFID public logistics information sharing and exchanging solution," International Journal of Manufacturing Technology and Management, vol. 21, no. 3-4, pp. 254-268, 2010.

[9] S. C. Kulp, H. L. Lee, and E. Ofek, "Manufacturer benefits from information integration with retail customers," Management Science, vol. 50, no. 4, pp. 431-444, 2004.

[10] W. K. Chiang and Y. Feng, "The value of information sharing in the presence of supply uncertainty and demand volatility," 
International Journal of Production Research, vol. 45, no. 6 , pp. 1429-1447, 2007.

[11] H. S. Hsu, C. A. Alexander, and Z. Zhu, "Understanding the reverse logistics operations of a retailer: a pilot study," Industrial Management and Data Systems, vol. 109, no. 4, pp. 515-531, 2009.

[12] R. Klein and A. Rai, "Interfirm strategic information flows in logistics supply chain relationships," MIS Quarterly, vol. 33, no. 4, pp. 735-762, 2009.

[13] R. Angeles, "Anticipated IT infrastructure and supply chain integration capabilities for RFID and their associated deployment outcomes," International Journal of Information Management, vol. 29, no. 3, pp. 219-231, 2009.

[14] E. Bottani, M. Bertolini, R. Montanari, and A. Volpi, "RFIDenabled business intelligence modules for supply chain optimisation," International Journal of RF Technologies: Research and Applications, vol. 1, no. 4, pp. 253-278, 2009.

[15] R. J. Kauffman and H. Mohtadi, "Information sharing and strategic signaling in supply chains," Journal of Systems Science and Systems Engineering, vol. 18, no. 2, pp. 129-158, 2009.

[16] D. Hellstrom, C. Johnsson, and A. Norrman, "Risk and gain sharing challenges in interorganisational implementation of RFID technology," International Journal of Procurement Management, vol. 4, no. 5, pp. 513-534, 2011.

[17] J. J. Nativi and S. Lee, "Impact of RFID information-sharing strategies on a decentralized supply chain with reverse logistics operations," International Journal of Production Economics, vol. 136, no. 2, pp. 366-377, 2012.

[18] A. Khare and A. Khare, "Harnessing supply chain efficiency through information linkages: case of multi national companies and small retail sector in India," International Journal of Information Systems and Supply Chain Management, vol. 5, no. 4, pp. 86-104, 2012.

[19] B. Jiang and L. Teng, "Vendor managed inventory integration on pharmaceutical third-party logistics," International Journal of Multimedia and Ubiquitous Engineering, vol. 11, no. 6, pp. 397-410, 2016.

[20] Z. Li, "A study of agricultural products distribution using the internet of things," International Journal of Simulation: Systems, Science and Technology, vol. 17, no. 19, pp. 13.11-13.15, 2016.

[21] Y. C. Liu and H. M. Gao, "An empirical case study for the application of agricultural product traceability system," in Advances in Intelligent Systems and Computing, pp. 210-217, Springer, Berlin, Germany, 2020.

[22] W. Wu, Y. Deng, M. Zhang, and Y. Zhang, "Performance evaluation on aquatic product cold-chain logistics," Journal of Industrial Engineering and Management, vol. 8, no. 5, pp. 1746-1768, 2015.

[23] S. Jian and Z. Jing, "Evaluation of core competence of coldchain logistics enterprises based on FCE model," The Open Cybernetics \& Systemics Journal, vol. 9, no. 1, pp. 2605-2613, 2015.

[24] W. Jiang, Z. Hu, Y. Liang, and Y. Chen, "Modeling and optimization of food cold-chain intelligent logistics distribution network," Advance Journal of Food Science and Technology, vol. 7, no. 8, pp. 573-578, 2015.

[25] S. Wang, F. Tao, Y. Shi, and H. Wen, "Optimization of vehicle routing problem with time windows for cold chain logistics based on carbon tax," Sustainability (Switzerland), vol. 9, no. 5 , p. 694, 2017.

[26] A. Gallo, R. Accorsi, G. Baruffaldi, and R. Manzini, "Designing sustainable cold chains for long-range food distribution: energy-effective corridors on the silk road belt," Sustainability (Switzerland), vol. 9, no. 11, 2017.

[27] A. E. Osorio, M. G. Corradini, and G. Dewi, "In-store cold chain failures: food safety considerations," Journal of Marketing Channels, vol. 24, no. 3-4, pp. 153-170, 2017.

[28] I. Ali, S. Nagalingam, and B. Gurd, "A resilience model for cold chain logistics of perishable products," The International Journal of Logistics Management, vol. 29, no. 3, pp. 922-941, 2018.

[29] A. Chaudhuri, I. Dukovska-Popovska, N. Subramanian, H. K. Chan, and R. Bai, "Decision-making in cold chain logistics using data analytics: a literature review," The International Journal of Logistics Management, vol. 29, no. 3, pp. 839-861, 2018.

[30] X. Li and Z. Wang, "Multidimensional context-aware recommendation algorithm towards intelligent distribution of cold chain logistics," Journal of Intelligent \& Fuzzy Systems, vol. 35, no. 1, pp. 171-185, 2018.

[31] S. Wang, "Developing value added service of cold chain logistics between China and Korea," Journal of Korea Trade, vol. 22, no. 3, pp. 247-264, 2018.

[32] L. Chen, M. Ma, and L. Sun, "Heuristic swarm intelligent optimization algorithm for path planning of agricultural product logistics distribution," Journal of Intelligent \& Fuzzy Systems, vol. 37, no. 4, pp. 4697-4703, 2019.

[33] L. Li, Y. Yang, and G. Qin, "Optimization of integrated inventory routing problem for cold chain logistics considering carbon footprint and carbon regulations," Sustainability (Switzerland), vol. 11, no. 17, 2019.

[34] S. K. Mangla, Y. K. Sharma, P. P. Patil, G. Yadav, and J. Xu, "Logistics and distribution challenges to managing operations for corporate sustainability: study on leading Indian diary organizations," Journal of Cleaner Production, vol. 238, 2019.

[35] C. Wei, W.-W. Gao, Z.-H. Hu, Y.-Q. Yin, and S.-D. Pan, "Assigning customer-dependent travel time limits to routes in a cold-chain inventory routing problem," Computers \& Industrial Engineering, vol. 133, pp. 275-291, 2019.

[36] N. Al Theeb, H. J. Smadi, T. H. Al-Hawari, and M. H. Aljarrah, "Optimization of vehicle routing with inventory allocation problems in cold supply chain logistics," Computers and Industrial Engineering, vol. 142, 2020.

[37] S. Barari, G. Agarwal, W. J. Zhang, B. Mahanty, and M. K. Tiwari, "A decision framework for the analysis of green supply chain contracts: an evolutionary game approach," Expert Systems with Applications, vol. 39, no. 3, pp. 29652976, 2012.

[38] J. Li, W. Du, F. Yang, and G. Hua, "Evolutionary game analysis of remanufacturing closed-loop supply chain with asymmetric information," Sustainability, vol. 6, no. 9, pp. 6312-6324, 2014.

[39] Y. Tian, K. Govindan, and Q. Zhu, "A system dynamics model based on evolutionary game theory for green supply chain management diffusion among Chinese manufacturers," Journal of Cleaner Production, vol. 80, pp. 96-105, 2014.

[40] P. Ji, X. Ma, and G. Li, "Developing green purchasing relationships for the manufacturing industry: an evolutionary game theory perspective," International Journal of Production Economics, vol. 166, pp. 155-162, 2015.

[41] A. Hafezalkotob and R. Mahmoudi, "Selection of energy source and evolutionary stable strategies for power plants under financial intervention of government," Journal of Industrial Engineering International, vol. 13, no. 3, pp. 357-367, 2017. 
[42] G. Zhu, G. Pan, and W. Zhang, "Evolutionary game theoretic analysis of low carbon investment in supply chains under governmental subsidies," International Journal of Environmental Research and Public Health, vol. 15, no. 11, 2018.

[43] Z. Li, G. Jin, and S. Duan, "Evolutionary game dynamics for financial risk decision-making in global supply chain," Complexity, vol. 2018, Article ID 9034658, 10 pages, 2018.

[44] R. Mahmoudi and M. Rasti-Barzoki, "Sustainable supply chains under government intervention with a real-world case study: an evolutionary game theoretic approach," Computers \& Industrial Engineering, vol. 116, pp. 130-143, 2018.

[45] A. Hafezalkotob, R. Mahmoudi, E. Hajisami, and H. M. Wee, "Wholesale-retail pricing strategies under market risk and uncertain demand in supply chain using evolutionary game theory," Kybernetes, vol. 47, no. 6, pp. 1178-1201, 2018.

[46] Q. Shi, J. Zhu, and Q. Li, "Cooperative evolutionary game and applications in construction supplier tendency," Complexity, vol. 2018, Article ID 8401813, 13 pages, 2018.

[47] T. Shu, Y. Wang, S. Chen, S. Wang, K. K. Lai, and Y. Yang, "Analysis of evolutionary game in structural formation of market power in remanufacturing supply chains," Applied Economics, vol. 51, no. 20, pp. 2195-2220, 2019.

[48] H. Sun, Y. Wan, L. Zhang, and Z. Zhou, "Evolutionary game of the green investment in a two-echelon supply chain under a government subsidy mechanism," Journal of Cleaner Production, vol. 235, pp. 1315-1326, 2019.

[49] K. Kang, Y. Zhao, J. Zhang, and C. Qiang, "Evolutionary game theoretic analysis on low-carbon strategy for supply chain enterprises," Journal of Cleaner Production, vol. 230, pp. 981-994, 2019.

[50] C. Hao, Q. Du, Y. Huang, L. Shao, and Y. Yan, "Evolutionary game analysis on knowledge-sharing behavior in the construction supply chain," Sustainability (Switzerland), vol. 11, no. 19, 2019.

[51] J. Xu, J. Cao, Y. Wang, X. Shi, and J. Zeng, "Evolutionary game on government regulation and green supply chain decisionmaking," Energies, vol. 13, no. 3, 2020.

[52] Zion Market Research, Cold Chain Market by Type (Refrigerated Storage and Transport), by Temperature Type (Chilled and Frozen), and by Application (Dairy \& Frozen Desserts; Meat, Fish, and Seafood, Fruits \& Vegetables, Bakery \& Confectionery, Pharmaceuticals, and Others)—Global Industry Perspective, Comprehensive Analysis and Forecast, 2017-2024, 2017, https://www.zionmarketresearch.com/ report/cold-chain-market.

[53] K. Cai, S. He, and Z. He, "Information sharing under different warranty policies with cost sharing in supply chains," International Transactions in Operational Research, vol. 27, no. 3, pp. 1550-1572, 2020.

[54] M. A. Abd, S. F. Al Rubeaai, S. Salimpour, and A. Azab, "Evolutionary game theoretical approach for equilibrium of cross-border traffic," Transportmetrica B: Transport Dynamics, vol. 7, no. 1, pp. 1611-1626, 2019. 